\title{
Extending the models for iron and sulfur oxidation in the extreme Acidophile Acidithiobacillus ferrooxidans Raquel Quatrini ${ }^{\dagger 1}$, Corinne Appia-Ayme ${ }^{\dagger 2,5}$, Yann Denis ${ }^{3}$, Eugenia Jedlicki ${ }^{4}$, David S Holmes ${ }^{1}$ and Violaine Bonnefoy*2
}

\begin{abstract}
Address: ${ }^{1}$ Center for Bioinformatics and Genome Biology, MIFAB, Fundación Ciencia para la Vida and Depto. de Ciencias Biologicas, Facultad de Ciencias de la Salud, Universidad Andres Bello, Santiago, Chile, ${ }^{2}$ Laboratoire de Chimie Bactérienne, Institut de Microbiologie de la Méditerranée, Centre National de la Recherche Scientifique, Marseille, France, ${ }^{3}$ Platforme Transcriptome, Institut de Microbiologie de la Méditerranée, Centre National de la Recherche Scientifique, Marseille, France, ${ }^{4}$ Cellular and Molecular Biology, Faculty of Medicine, University of Chile, Santiago, Chile and ${ }^{5}$ Institute for Food Research, Norwich Research Park, Colney Lane, Norwich, NR4 7AU, UK

Email: Raquel Quatrini - rquatrini@yahoo.com.ar; Corinne Appia-Ayme - appiaayme@gmail.com; Yann Denis - ydenis@ifr88.cnrs-mrs.fr; Eugenia Jedlicki - e.jedlicki@yahoo.com; David S Holmes - dsholmes2000@yahoo.com; Violaine Bonnefoy* - bonnefoy@ifr88.cnrs-mrs.fr * Corresponding author †Equal contributors
\end{abstract}

Published: 24 August 2009

BMC Genomics 2009, 10:394 doi:10.1 |86/147|-2164-10-394
Received: 17 May 2009

Accepted: 24 August 2009

This article is available from: http://www.biomedcentral.com/I47I-2/64/10/394

(c) 2009 Quatrini et al; licensee BioMed Central Ltd.

This is an Open Access article distributed under the terms of the Creative Commons Attribution License (http://creativecommons.org/licenses/by/2.0), which permits unrestricted use, distribution, and reproduction in any medium, provided the original work is properly cited.

\begin{abstract}
Background: Acidithiobacillus ferrooxidans gains energy from the oxidation of ferrous iron and various reduced inorganic sulfur compounds at very acidic $\mathrm{pH}$. Although an initial model for the electron pathways involved in iron oxidation has been developed, much less is known about the sulfur oxidation in this microorganism. In addition, what has been reported for both iron and sulfur oxidation has been derived from different $A$. ferrooxidans strains, some of which have not been phylogenetically characterized and some have been shown to be mixed cultures. It is necessary to provide models of iron and sulfur oxidation pathways within one strain of $A$. ferrooxidans in order to comprehend the full metabolic potential of the pangenome of the genus.

Results: Bioinformatic-based metabolic reconstruction supported by microarray transcript profiling and quantitative RT-PCR analysis predicts the involvement of a number of novel genes involved in iron and sulfur oxidation in A. ferrooxidans ATCC23270. These include for iron oxidation: cup (copper oxidase-like), ctaABT (heme biogenesis and insertion), nuol and nuoK (NADH complex subunits), sdrAl (a NADH complex accessory protein) and atpB and atpE (ATP synthetase F0 subunits). The following new genes are predicted to be involved in reduced inorganic sulfur compounds oxidation: a gene cluster ( $r h d, t u s A, d s r E, h d r C, h d r B, h d r A$, orf2, $h d r C, h d r B$ ) encoding three sulfurtransferases and a heterodisulfide reductase complex, sat potentially encoding an ATP sulfurylase and sdrA2 (an accessory NADH complex subunit). Two different regulatory components are predicted to be involved in the regulation of alternate electron transfer pathways: I) a gene cluster (ctaRUS) that contains a predicted iron responsive regulator of the Rrf2 family that is hypothesized to regulate cytochrome $a a_{3}$ oxidase biogenesis and 2) a two component sensor-regulator of the RegB-RegA family that may respond to the redox state of the quinone pool.

Conclusion: Bioinformatic analysis coupled with gene transcript profiling extends our understanding of the iron and reduced inorganic sulfur compounds oxidation pathways in $A$. ferrooxidans and suggests mechanisms for their regulation. The models provide unified and coherent descriptions of these processes within the type strain, eliminating previous ambiguity caused by models built from analyses of multiple and divergent strains of this microorganism.
\end{abstract}




\section{Background}

Acidithiobacillus ferrooxidans is an acidophilic, chemolithoautotrophic $\gamma$-proteobacterium that uses energy and electrons derived from the oxidation of ferrous iron (Fe(II)) and reduced inorganic sulfur compounds (RISCs) for carbon dioxide and nitrogen fixation and other anabolic processes. It is a member of a consortium of microorganisms used for industrial copper recovery (bioleaching or biomining) and gold recovery (biooxidation) and contributes to the geobiochemical recycling of metals and nutrients in pristine and contaminated acid-rich environments.

When A. ferrooxidans requires reducing power it is confronted by a particularly challenging bioenergetic problem because the standard reduction half-potential of the $\mathrm{Fe}(\mathrm{II}) / \mathrm{Fe}(\mathrm{III})$ couple $(+0.77 \mathrm{~V}$ at $\mathrm{pH} 2$, the $\mathrm{pH}$ of the medium) is much more positive than that of the NAD(P)/ $\mathrm{NAD}(\mathrm{P}) \mathrm{H}$ couple $(-0.32 \mathrm{~V}$ at the cytoplasmic $\mathrm{pH} 7)$. This means that electrons have to be "pushed uphill" from $\mathrm{Fe}(\mathrm{II})$ to $\mathrm{NAD}(\mathrm{P})$ against the redox potential gradient (uphill pathway). The energy to accomplish this was proposed to come from the proton motive force that naturally occurs across the periplasmic membrane of $A$. ferrooxidans (outside $=\mathrm{pH} 2$, inside $=\mathrm{pH}$ 7). It was further suggested that protons, entering the cell through a membrane associated ATP synthetase, could be consumed during the reduction of oxygen to water $\left(2 e^{-}+1 / 2 \mathrm{O}_{2}+2 \mathrm{H}^{+}\right.$ $\rightarrow \mathrm{H}_{2} \mathrm{O}$ ) in which electrons for this reaction come from the oxidation of $\mathrm{Fe}(\mathrm{II})$ in a pathway that is thermodynamically favorable (downhill pathway). These ideas were first promulgated based upon theoretical considerations by Ingledew [1] but the model has been extended more recently and major parts of it are now supported by experimental evidence (reviewed in [2]).

According to the model (see Figure 1), components involved in the downhill electron pathway from $\mathrm{Fe}(\mathrm{II})$ to oxygen include: an outer membrane high molecularweight cytochrome $c$ encoded by $c y c 2$, a gene of unknown function (ORF1), a periplasmic soluble blue copper protein rusticyanin encoded by rus, a periplasmic membranebound dihemic cytochrome $c_{4}$ encoded by $c y c 1$ and a terminal cytochrome oxidase of the $a a_{3}$-type encoded by the coxBACD gene cluster [3-6]. In A. ferrooxidans ATCC 33020 these genes are cotranscribed in an eight gene transcriptional unit, termed the rus operon that is upregulated in $\mathrm{Fe}(\mathrm{II})$-grown cells [5,7]. Gene context analysis of the recently annotated genomic sequence of $A$. ferrooxidans

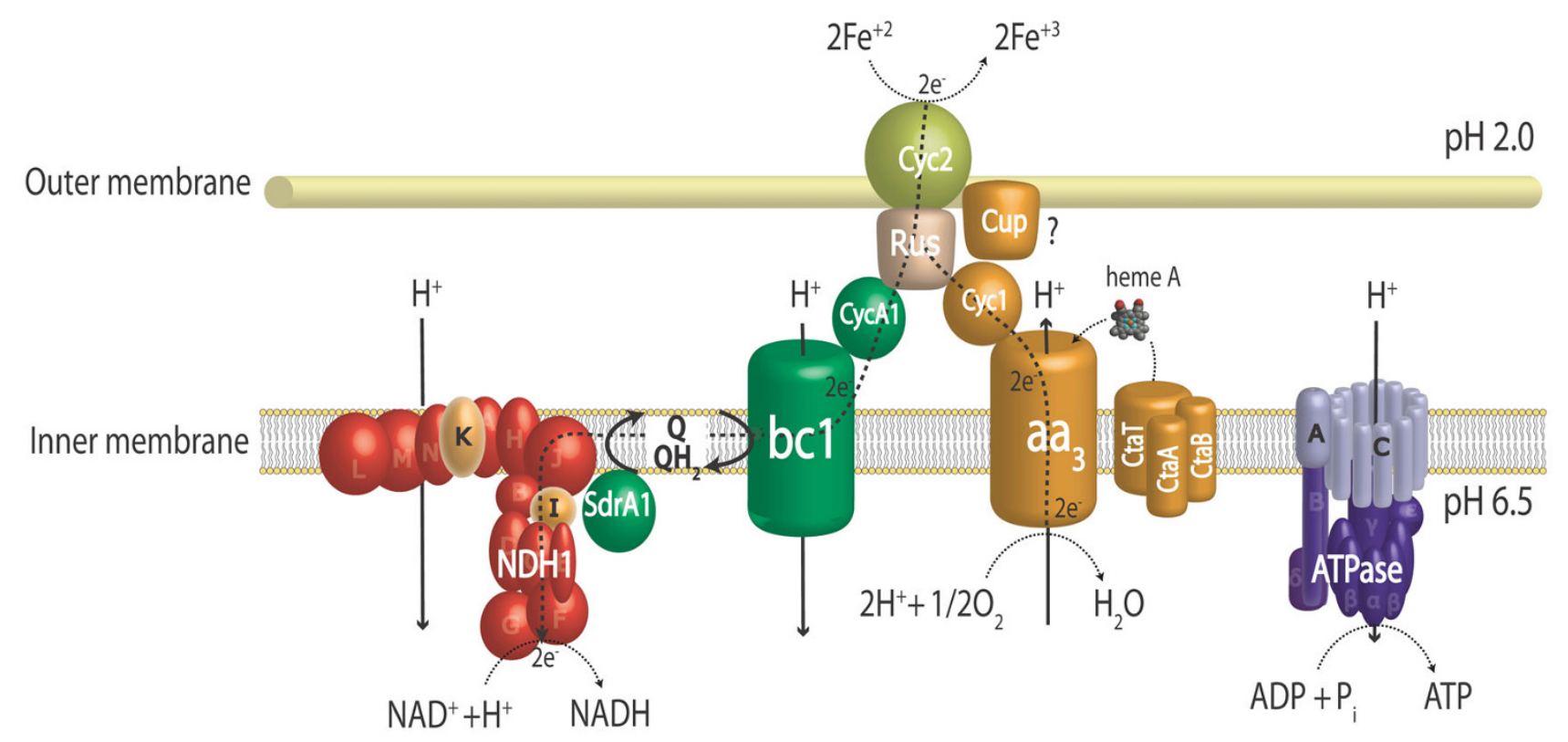

Figure I

Model of Fe(II) oxidation in A. ferrooxidans ATCC 23270 . The flow of electrons is shown from the oxidation of Fe ${ }^{+2}$ by

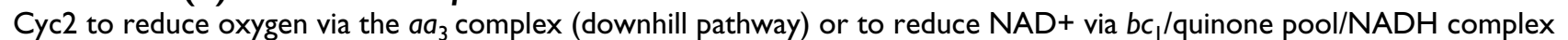
(uphill pathway). The downhill pathway can consume protons entering via the ATPase complex helping to drive ATP synthesis or via the $b c_{1}$ /quinone pool/NADH complex that drives the flow of electrons in the uphill pathway. The switch point between the downhill and uphill flow is suggested to be at the level of rusticyanin (Rus). Abbreviations used can be found in the text. 
type strain ATCC 23270 demonstrates that the rus operon is similarly organized in this strain [8].

The uphill components include: a cytochrome $b c_{1}$ complex (complex III, ubiquinol-cytochrome $c$ reductase), the quinone pool and a NADH1 dehydrogenase complex (hereafter abbreviated to NADH complex) functioning in reverse [9-11]. Genetic and biophysical evidence obtained for A. ferrooxidans ATCC 19859 and ATCC 33020 support this view [11-13]. In these two strains, the genes encoding the $b c_{1}$ complex have been shown to be part of a five-gene operon, termed the petI operon, mainly transcribed in $\mathrm{Fe}(\mathrm{II})$ conditions and organized as following: a diheme cytochrome $c_{4}(c y c A 1)$, a short-chain dehydrogenase (sdrA1) of unknown function, a cytochrome $b$ (petA1), an iron-sulfur protein Rieske (petB1), and a cytochrome $c_{1}$ (petC1) $[2,12,13]$. Based on the cotranscription of the diheme cytochrome $c_{4}$ gene ( $\left.c y c A 1\right)$ with those encoding the $b c_{1}$ complex, it was proposed that electrons from the diheme cytochrome $c_{4}$ take a thermodynamically uphill pathway via the $b c_{1}$ complex to a NADH complex driven energetically by proton motive force $[2,12-14]$ (see Figure 1 ). Adjacent to the petI operon, is a three gene (resBC and a hypothetical gene) operon in which ResBC are predicted to be chaperones involved in heme insertion in $c$-type cytochromes, possibly those involved in the maturation of the $c_{1}$ cytochrome of the $b c_{1}$ complex [12]. The petI operon is similarly organized and transcribed in A. ferrooxidans ATCC 23270 [14] supporting this model.

The bifurcation in the flow of electrons from $\mathrm{Fe}(\mathrm{II})$ to reduce either NAD (uphill) or $\mathrm{O}_{2}$ (downhill) has been proposed to occur at the level of rusticyanin, a small periplasmic blue copper protein $[2,13,14]$ (see Figure 1). By adjusting the flow of electrons at this branch point, it was suggested that $A$. ferrooxidans could balance its requirements for NADH and ATP [9].

The components involved in both the uphill and downhill electron flow have been shown to form a Fe-oxidizing/ $\mathrm{O}_{2}$-reducing supercomplex spanning both inner and outer membranes in an unnamed strain of $A$. ferrooxidans [15] supporting previous models. The supercomplex has also been suggested to include a copper containing protein (ORF1) physically associated with the periplasmic Cyc1 that is proposed to be involved in downhill electron flow. In addition, in vitro reconstitution of the iron oxidation system of the A. ferrooxidans type strain with rusticyanin, $a a_{3}$-type cytochrome oxidase, the cytochromes $c$ Cyc2 and Cyc1 has been reported recently [16].

Despite progress in understanding iron oxidation in the Acidithiobacillus genus, several lacunae in our knowledge persist, such as the identification of components involved in the proposed connection between the $b c_{1}$ /quinone complex and the NADH complex, the identification of the chaperones used for cofactor insertion into the relevant redox proteins, and the mechanisms and components regulating the electron flux via the downhill pathway to $\mathrm{O}_{2}$ versus the uphill pathway to the NADH complex.

Reduced inorganic sulfur oxidation is widespread in prokaryotes (reviewed in $[17,18]$. However, in contrast to iron that occurs in only two oxidation states, sulfur exists in multiple states from -2 to +6 , complicating identification of intermediates and relevant enzymes in sulfur oxidation. Also, some sulfur compounds can be oxidized abiotically adding further difficulties in resolving enzymatic steps from chemical changes. Despite these difficulties, several biological pathways for RISCs oxidation have been identified including the phylogenetically widespread sulfur oxidizing (sox) gene pathway (reviewed in [17]) and the archaeal type sulfur oxygenase reductase (sor) gene system (reviewed in [19]). However, neither sox, nor sor have been detected in the genome of A. ferrooxidans $[2,8]$, raising the question as to how this organism oxidizes RISCs.

Much of our knowledge of RISCs oxidation in A. ferrooxidans comes from enzyme assays performed many years ago on different strains, some of which await phylogenetic characterization or, in some cases, have not yet even been isolated as pure cultures [2]. Those that have been characterized form genetically diverse clusters with at least three phylogenetic groups [20-23]. This raises the possibility that current models of RISCs oxidation reflect a patchwork assemblage of predicted pathways and activities that may not exist in toto in any one A. ferrooxidans strains and perhaps more accurately reflect the pangenomic capacity of the genus Acidithiobacillus for RISCs oxidation.

Thus the current investigation was prompted by the need to generate a more comprehensive picture of iron and sulfur bioenergetics by searching for missing steps and predicting novel enzymatic and electron transfer components and to provide a coherent picture of these processes in one strain of A. ferrooxidans (type strain, ATCC 23270), facilitating the recognition of species variation in bioenergetic pathways.

\section{Results and Discussion General Features of the Transcriptional Profiles}

RNA, isolated from mid-log A. ferrooxidans grown in either sulfur $\left(\mathrm{S}^{0}\right)$ or ferrous iron (Fe(II)) medium, was used to probe gene expression using microarrays displaying unique oligonucleotides representing about 3000 predicted genes of the A. ferrooxidans type strain genome. Using statistical criteria described previously [14], a 1.5 log ratio of median cut-off (corresponding to genes induced more than 2.8 fold) was selected as indicating 
differential gene expression in the two growth conditions (Table 1[7,24,25], Table 2[24-29] and Additional file $1[7,24-26,29])$. The expression patterns observed with the microarrays were validated for some relevant genes by real-time quantitative PCR (Table 3[7,24-26,28,29]). One hundred and ninety four genes presented a differential expression profile, of which 110 were upregulated (up to 38 fold) while 84 were downregulated (up to 10 fold) in iron compared to sulfur medium. Genes exhibiting differential expression were grouped by hierarchical clustering and were found to be mostly associated with unknown functions, energy metabolism, cell envelope and central intermediary processes (Additional file 1[7,24-26,29]).

\section{Extending the current model of $\mathrm{Fe}$ (II) oxidation}

The rus operon was induced in $\mathrm{Fe}(\mathrm{II})$-grown cells (Table $1[7,24,25]$ and Table $3[7,24-26,28,29])$ supporting the current model of the involvement of Cyc2, rusticyanin, $\mathrm{Cyc1}$ and cytochrome oxidase in the oxidation of $\mathrm{Fe}(\mathrm{II})$ and the downhill electron transfer chain terminating in the reduction of oxygen to water (Figure 1).

Embedded in the rus gene operon, is a hypothetical gene of unknown function (ORF1, AFE_3151). Its genetic linkage and congruent transcriptional activity suggest that it is involved in $\mathrm{Fe}(\mathrm{II})$ oxidation (Table $1[7,24,25]$ and Table $3[7,24-26,28,29])$. In agreement with these data, highest expression of ORF1 was detected in iron-compared to sulfur-grown ATCC 33020 cells [7]. ORF1 exhibits weak similarity to the putative type- 3 multicopper oxidase from Halorubrum lacusprofundi (30\% similarity, e-value: $8 \mathrm{e}-05$ ) and to the predicted outer membrane type 3 multicopper oxidase protein Pan 1 from Halobacterium sp. NRC-1 (32\% similarity; e-value: $3 e-04)$. It also exhibits weak similarity to rusticyanin including conservation of three out of its four critical copper binding residues. In addition, EPR analysis suggests that ORF1 contains copper [30]. We propose the name Cup (cupredoxin-like) for ORF1. A possible function for Cup is to deliver copper either to $a a_{3}$ cytochrome oxidase or to rusticyanin. The well documented proteins Sco and Cox1 that are involved in copper delivery to copper-containing proteins in other organisms [31] have been not detected in A. ferrooxidans [8] and Cup may have assumed their role. Given its similarity to rusticyanin, an alternate hypothesis is that Cup is involved in electron transfer perhaps between Cyc2 and Cyc1 bypassing rusticyanin. Two arguments in favor of this hypothesis are: 1) Cup has been shown experimentally to be physically associated with Cyc1 and not with rusticyanin [15], and 2) Cup is bound to the outer membrane likely facing the periplasm [Amouric, Yarzabal and Bonnefoy, unpublished results]. Cup could provide an alternative route for electron flow during iron oxidation and an additional point for its regulation.
Immediately downstream of the rus operon is a cluster of six genes, upregulated in iron (Table $1[7,24,25]$ and Table $3[7,24-26,28,29])$, that are predicted to be involved in cytochrome $a a_{3}$ oxidase biogenesis (ctaABT) and ironresponsive regulation of cytochrome $a a_{3}$ oxidase biogenesis (ctaRUS): ctaA (AFE_3144) encoding an integral membrane protein with 7 out of 8 His located in transmembrane regions similar to heme A synthase CtaA ([32] and references therein), ctaB (AFE_3143) encoding a heme $\mathrm{O}$ synthase and ctaT (AFE_3142) encoding an integral membrane protein belonging to the major facilitator family transporter that could be involved in the exportation of heme A to cytochrome oxidase [33] (Figure 1); ctaR (AFE_3141) predicted to encode an iron responsive regulator [34] of the Rrf2 family that in T. denitrificans is clustered with $c b b_{3}$ cytochrome oxidase biogenesis genes (data not shown), ctaU (AFE_3139) encoding a hypothetical protein of unknown function and ctaS (AFE_3138) encoding a predicted $\mathrm{Fe}(\mathrm{II})$-dependent oxygenase superfamily member of unknown function. Immediately downstream but transcribed in the other direction, are two genes regBA (AFE_3136-3137), also upregulated in iron (Table $1[7,24,25]$ and Table $3[7,24-26,28,29])$, that are predicted to encode a sensor/regulator two-component signal transduction system of the RegB/RegA family with similarity to RegBA of Rhodobacter capsulatus. RegA directly controls synthesis of cytochrome $c b b_{3}$ and ubiquinol oxidases that function as terminal electron acceptors in a branched respiratory chain [35]. Given the sequence similarity of the predicted A. ferrooxidans RegA with that of R. capsulatus, the conservation of the quinone binding site in the membrane spanning domain and of the redox active cysteine in the cytoplasmic transmitter domain of RegB, we propose that it is also involved in redox sensing. Because of the regBA juxtaposition to genes predicted to encode cytochrome $a a_{3}$ oxidase biogenesis, this cytochrome oxidase is a likely candidate for the target of RegBA regulation in A. ferrooxidans. However, in R. capsulatus, RegBA also regulates other genes involved in respiratory electron components such as cytochromes $c_{2}, \mathrm{c}(\mathrm{y})$ and the cytochrome $b c_{1}$ complex, so that the actual RegBA target(s) in A. ferrooxidans requires experimental evaluation. RegBA of $R$. capsulatus have been shown to respond to the status of the aerobic respiratory chain, most likely the ubiquinone pool in the membrane [36] and, if this also proves to be the case in A. ferrooxidans, RegBA could help in making regulatory changes to balance electron equivalents between uphill and downhill electron flow, perhaps by adjusting the proportion of cytochrome Cyc1 and cytochrome oxidase $a a_{3}$ (downhill electron flow) to the cytochrome CycA1 and the cytochrome $b c_{1}$ complex (uphill electron flow). Alternately, RegBA could play a role in switching between iron and sulfur oxidation or between aerobic and anaerobic oxidation. It is clear that the discovery of the predicted iron and redox responsive 
Table I: Microarray expression data for iron induced genes

\begin{tabular}{|c|c|c|c|c|c|}
\hline ID NC0II76I & Gene & Function & $\log _{2}$ ratio median & $\begin{array}{l}\text { One sample } \\
\text { t-Test } \\
\text { (p-value) }\end{array}$ & $\begin{array}{l}\text { Proteomic data: } \\
\text { references }\end{array}$ \\
\hline \multicolumn{6}{|l|}{ pet I operon } \\
\hline AFE_3III & petCl & $\begin{array}{l}\text { ubiquinol-cytochrome } \mathrm{c} \text { reductase, } \\
\text { cytochrome } \mathrm{cl} \text { subunit }\end{array}$ & 3,7 & $0,00 *$ & \\
\hline AFE_3IIO & petBI & $\begin{array}{l}\text { ubiquinol-cytochrome } c \text { reductase, } \\
\text { cytochrome } b \text { subunit }\end{array}$ & 4,4 & $0,00 *$ & \\
\hline AFE_3109 & petAl & $\begin{array}{l}\text { ubiquinol-cytochrome c reductase, } \\
\text { iron-sulfur subunit }\end{array}$ & 3,7 & $0,00 *$ & CCM 4252/[24] \\
\hline AFE_3108 & sdrAl & $\begin{array}{l}\text { oxidoreductase, short-chain } \\
\text { dehydrogenase/reductase family }\end{array}$ & 3,9 & $0,00 *$ & \\
\hline \multicolumn{6}{|l|}{ rus operon } \\
\hline AFE_3I53 & сус2 & cytochrome $c$ & 2,5 & $0,00^{*}$ & ATCC 33020/[7] \\
\hline AFE_3152 & cycl & cytochrome $c 552$ & 2,8 & $0,00 *$ & $\begin{array}{l}\text { ATCC } 33020 /[7] \\
\text { CCM 4253/[24] } \\
\text { ATCC } 19859 /[25]\end{array}$ \\
\hline AFE_3I5I & cup & conserved hypothetical protein & 3,1 & $0,00^{*}$ & ATCC 33020/[7] \\
\hline AFE_3I50 & $\operatorname{cox} B$ & $\begin{array}{l}\text { cytochrome c oxidase, aa3-type, } \\
\text { subunit II }\end{array}$ & 2,9 & $0,00 *$ & ATCC $33020 /[7]$ \\
\hline AFE_3149 & $\operatorname{cox} A$ & $\begin{array}{l}\text { cytochrome c oxidase, aa3-type, } \\
\text { subunit I }\end{array}$ & 2,5 & $0,00 *$ & ATCC $33020 /[7]$ \\
\hline AFE_3148 & $\operatorname{cox} C$ & $\begin{array}{l}\text { cytochrome c oxidase, aa3-type, } \\
\text { subunit III }\end{array}$ & $\mathrm{I}, 7$ & $0,02 *$ & ATCC 33020/[7] \\
\hline AFE_3I46 & rus & rusticyanin & $\mathrm{I}, 6$ & $0,00 *$ & $\begin{array}{l}\text { ATCC } 33020 /[7] \\
\text { CCM 4253/[24] } \\
\text { ATCC } 19859 /[25]\end{array}$ \\
\hline AFE_3146 & rus & rusticyanin & 2,1 & $0,00 *$ & $\begin{array}{l}\text { ATCC } 33020 /[7] \\
\text { CCM 4253/[24] } \\
\text { ATCC } 19859 /[25]\end{array}$ \\
\hline AFE_3146 & rus & rusticyanin & 1,9 & $0,00 *$ & $\begin{array}{l}\text { ATCC } 33020 /[7] \\
\text { CCM } 4253 /[24] \\
\text { ATCC } 19859 /[25]\end{array}$ \\
\hline \multicolumn{6}{|c|}{ Cytochrome c oxidase complex biogenesis operon } \\
\hline AFE_3I44 & $\operatorname{ctaA}$ & heme $A$ synthase & 2,4 & $0,00^{*}$ & \\
\hline AFE_3143 & $c t a B$ & $\begin{array}{l}\text { heme O synthase, protoheme IX } \\
\text { farnesyltransferase }\end{array}$ & 0,4 & 0,18 & \\
\hline AFE_3142 & ctaT & major facilitator family transporter & 0,8 & $0,00 *$ & \\
\hline AFE_314I & $c t a R$ & $\begin{array}{l}\text { iron responsive regulator of the } \\
\text { Rrf2 family }\end{array}$ & ND & ND & \\
\hline AFE_3139 & $\mathrm{ctaU}$ & hypothetical protein & 1,8 & $0,00 *$ & \\
\hline AFE_3138 & ctas & $\begin{array}{l}\text { oxidoreductase, 2OG-Fe(II) } \\
\text { oxygenase family }\end{array}$ & $\mathrm{I}, 4$ & $0,00^{*}$ & \\
\hline \multicolumn{6}{|c|}{ Sensor/regulator two-component signal transduction system } \\
\hline AFE_3137 & regA & DNA-binding response regulator & 0,7 & 0,02 & \\
\hline AFE_3I36 & $\operatorname{reg} B$ & sensor histidine kinase & 2,0 & $0,00 *$ & \\
\hline \multicolumn{6}{|c|}{ NADH complex operon } \\
\hline AFE_2630 & nuoA & $\begin{array}{l}\text { NADH-quinone oxidoreductase, } \mathrm{A} \\
\text { subunit }\end{array}$ & $-0,1$ & 0,80 & \\
\hline AFE_2629 & nuoB & $\begin{array}{l}\mathrm{NADH} \text {-quinone oxidoreductase, B } \\
\text { subunit }\end{array}$ & 0,3 & 0,13 & \\
\hline AFE_2628 & nuoC & $\begin{array}{l}\text { NADH-quinone oxidoreductase, } \mathrm{C} \\
\text { subunit }\end{array}$ & 0,0 & 0,69 & \\
\hline AFE_2627 & nuoD & $\begin{array}{l}\mathrm{NADH} \text {-quinone oxidoreductase, } \mathrm{D} \\
\text { subunit }\end{array}$ & $-0,5$ & 0,64 & \\
\hline AFE_2626 & nuoE & $\begin{array}{l}\mathrm{NADH} \text {-quinone oxidoreductase, } \mathrm{E} \\
\text { subunit }\end{array}$ & $-1,1$ & 0,05 & \\
\hline
\end{tabular}


Table I: Microarray expression data for iron induced genes (Continued)

\begin{tabular}{|c|c|c|c|c|}
\hline AFE_2625 & nuoF & $\begin{array}{l}\text { NADH-quinone oxidoreductase, } \mathrm{F} \\
\text { subunit }\end{array}$ & 0,4 & 0,01 \\
\hline AFE_2624 & nuoG & $\begin{array}{l}\text { NADH-quinone oxidoreductase, G } \\
\text { subunit }\end{array}$ & $-0,2$ & 0,24 \\
\hline AFE_2623 & nuoH & $\begin{array}{l}\mathrm{NADH} \text {-quinone oxidoreductase, } \mathrm{H} \\
\text { subunit }\end{array}$ & $-0,7$ & 0,00 \\
\hline AFE_2622 & nuol & $\begin{array}{l}\text { NADH-quinone oxidoreductase, I } \\
\text { subunit }\end{array}$ & $\mathrm{I}, 4$ & $0,00 *$ \\
\hline AFE_262I & nuol & $\begin{array}{l}\text { NADH-quinone oxidoreductase, J } \\
\text { subunit }\end{array}$ & $-0,1$ & 0,21 \\
\hline AFE_2620 & nuok & $\begin{array}{l}\text { NADH-quinone oxidoreductase, } \mathrm{K} \\
\text { subunit }\end{array}$ & 0,9 & $0,03 *$ \\
\hline AFE_2619 & nuol & $\begin{array}{l}\text { NADH-quinone oxidoreductase, L } \\
\text { subunit }\end{array}$ & $-0,9$ & 0,00 \\
\hline AFE_2618 & nuoM & $\begin{array}{l}\text { NADH-quinone oxidoreductase, } \\
\text { M subunit }\end{array}$ & $-0,8$ & 0,00 \\
\hline AFE_26I7 & nuoN & $\begin{array}{l}\text { NADH-quinone oxidoreductase, } \\
\text { N subunit }\end{array}$ & $-0,4$ & 0,19 \\
\hline \multicolumn{5}{|c|}{ ATP synthetase complex operon } \\
\hline AFE_3209 & $\operatorname{atp} B$ & ATP synthase F0, A subunit & 1,8 & $0,00 *$ \\
\hline AFE_3208 & atp E & ATP synthase $F 0, C$ subunit & 1,4 & $0,00 *$ \\
\hline AFE_3207 & atpF & ATP synthase F0, B subunit & 0,4 & 0,01 \\
\hline AFE_3206 & atpH & ATP synthase FI, delta subunit & 0,4 & 0,02 \\
\hline AFE_3205 & $\operatorname{atp} A$ & ATP synthase $\mathrm{FI}$, alpha subunit & $-0,2$ & 0,99 \\
\hline AFE_3204 & atpG & ATP synthase $\mathrm{FI}$, gamma subunit & $-0,5$ & 0,23 \\
\hline AFE_3203 & $a t p D$ & ATP synthase $\mathrm{FI}$, beta subunit & 0,0 & 0,75 \\
\hline AFE_3202 & $\operatorname{atp} C$ & ATP synthase FI, epsilon subunit & $-0,6$ & 0,01 \\
\hline
\end{tabular}

Gene expression values ( $\log _{2}$ ratio of median) for all genes/operons alluded in the revised model of Fe(II) oxidation in A. ferrooxidans ATCC 23270 . Genes with a $\log _{2}$ ratio of median larger than $|1.5|$ (corresponding to genes induced more than 2.8 fold) are considered differentially expressed (indicated with $*$ ) and genes p-value $<0,005$ are considered significant. Gene ID is that of Genbank genome annotation NC 01 I 76 I. The reference and the strain in which the level of the gene product has been shown to be higher in Fe(II) than in $\mathrm{S}^{0}$ conditions are indicated in the last column. ND: not determined.

regulators CtaRUS and RegAB will now allow the experimental biologist to focus on important regulatory switches that are most likely to be involved in cellular decisions related to energy metabolism.

The petI operon was also induced in $\mathrm{Fe}(\mathrm{II})$ medium (Table $1[7,24,25]$ and Table $3[7,24-26,28,29])$ supporting the current model for the role of the $b c_{1}$ complex in the uphill flow of electrons during iron oxidation (Figure 1). Embedded within the petI operon is sdrA1 (AFE_3108) whose function remains unknown. SdrA1 has the characteristic NAD $(P)$ binding site at its N-terminus (TGAGE-

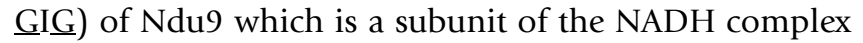
involved in this complex assembly and stability in a variety of eukaryotes [37]. However, SdrA1 exhibits the conserved catalytic residues (N125, S147, Y166, K170) involved in electron input into the NADH complex or electron transfer within the complex, suggesting that this protein could function as an oxidoreductase [38,39] (Additional file 2). SdrA1 has been predicted to be situated in the cytoplasm in A. ferrooxidans with a possible hydrophobic region embedded in the inner membrane [12] and we hypothesize that it transfers electrons from the quinone pool to the NADH complex (Figure 1).
Whereas most of the predicted genes encoding the subunits of the NADH complex (AFE_2630-2617) are equally expressed in $\mathrm{Fe}(\mathrm{II})$ and $\mathrm{S}^{0}$ growth conditions, nuoI (AFE_2622) and nuoK (AFE_2620) are upregulated in Fe(II) medium (Table 1[7,24,25]). The nuoI encodes a ferredoxin located in the cytoplasmic arm of the NADH complex and is involved in the intramolecular electron transfer between FMN and quinone, whereas nuoK encodes a membrane subunit thought to be involved in quinone reduction [40] and in proton translocation [41]. Given the predicted locations of NuoI and NuoK in the hinge region of the NADH complex [42] and the upregulation of nuoI, nuoK and sdrA1 in Fe(II) growth conditions, we suggest that they interact to facilitate uphill electron flow from quinone to the NADH complex (Figure 1).

Whereas most of the genes predicted to encode the ATP synthetase complex were similarly expressed in $\mathrm{Fe}$ (II) and in $S^{0}$ grown cells, membrane embedded F0 subunits A and C, encoded by atpB (AFE_3209) and atpE (AFE_3208) respectively, were upregulated in $\mathrm{Fe}(\mathrm{II})$ growth conditions (Table 1[7,24,25]). These subunits are involved in proton translocation across the membrane [43] and their upregulation could allow more protons to pass through the ATP synthetase complex during $\mathrm{Fe}(\mathrm{II})$ oxidation, provided an increase in ATP synthesis. However, the resulting increase 
Table 2: Microarray expression data for sulfur induced genes

\begin{tabular}{lllll}
\hline ID NCOII76I & Gene & Function & log $_{2}$ ratio median & $\begin{array}{l}\text { One sample } \\
\text { t-Test } \\
\text { (p-value) }\end{array}$ \\
\hline pet II operon & & & $\begin{array}{l}\text { Proteomic data: } \\
\text { strain/references }\end{array}$ \\
\hline AFE_2732 & hip & High potential iron-sulfur protein & $-1,8$ & $0,00^{*}$ \\
\hline AFE_273I & petC2 & ubiquinol-cytochrome c reductase, cytochrome cl subunit & $-0,3$ & 0,09 \\
\hline AFE_2730 & petB2 & ubiquinol-cytochrome c reductase, cytochrome b subunit & $-1,7$ & $0,00^{*}$ \\
\hline AFE_2729 & petA2 & ubiquinol-cytochrome c reductase, iron-sulfur subunit & $-1,9$ & $0,00^{*}$ \\
\hline AFE_2728 & sdrA2 & $\begin{array}{l}\text { oxidoreductase, short-chain dehydrogenase/reductase } \\
\text { family }\end{array}$ & $-1,1$ & $0,00^{*}$ \\
\hline AFE_2727 & cycA2 & cytochrome c4 & $-0,5$ & 0,17 \\
\hline
\end{tabular}

Heterodisulfide reductase complex operon

\begin{tabular}{|c|c|c|c|c|}
\hline AFE_2586 & $h d r B$ & heterodisulfide reductase subunit $B$, homolog & $-1,5$ & $0,00 *$ \\
\hline AFE_2558 & rhd & rhodanese-like domain protein & 0,1 & 0,38 \\
\hline AFE_2557 & tusA & conserved hypothetical protein & $-2,4$ & $0,00 *$ \\
\hline AFE_2556 & $d s r E$ & conserved hypothetical protein & $-2,1$ & $0,00 *$ \\
\hline AFE_2555 & hdrC & iron-sulfur cluster-binding protein & $-2,1$ & $0,00 *$ \\
\hline AFE_2554 & $h d r B$ & heterodisulfide reductase subunit $B$, homolog & $-2,0$ & $0,00 *$ \\
\hline AFE_2553 & $h d r A$ & pyridine nucleotide-disulfide oxidoreductase & $-2,6$ & $0,00 *$ \\
\hline AFE_2552 & orf2 & conserved hypothetical protein & ND & ND \\
\hline AFE_255I & hdrC & iron-sulfur cluster-binding protein & $-2,4$ & $0,00 *$ \\
\hline AFE_2550 & $h d r B$ & succinate dehydrogenase/fumarate reductase, $\mathrm{C}$ subunit & $-1,9$ & $0,00 *$ \\
\hline
\end{tabular}

\section{Sulfide-quinone reductase}

\begin{tabular}{|c|c|c|c|c|c|}
\hline AFE_I792 & sqr & sulfide-quinone reductase, putative & $-1,6$ & $0,00^{*}$ & $\begin{array}{l}\text { CCM } 4253 /[24] \\
\text { NASF-I/[26] }\end{array}$ \\
\hline
\end{tabular}

Cytochrome bd ubiquinol oxidase

\begin{tabular}{lllll}
\hline AFE_0955 & cydA & cytochrome d ubiquinol oxidase, subunit I & $-2,0$ & $0,00^{*}$ \\
\hline AFE_0954 & $c y d B$ & cytochrome d ubiquinol oxidase, subunit II & $-2,6$ & $0,00^{*}$ \\
\hline Cytochrome bo3 ubiquinol oxidase & & $0,00^{*}$ \\
\hline AFE_0634 & $c y 0 D$ & cytochrome o ubiquinol oxidase, subunit IV & $-2,3$ & \\
\hline
\end{tabular}


Table 2: Microarray expression data for sulfur induced genes (Continued)

\begin{tabular}{lclll}
\hline AFE_0633 & cyoC & cytochrome o ubiquinol oxidase, subunit III & $-3,0$ & $0,00^{*}$ \\
\hline AFE_0632 & cyoB & cytochrome o ubiquinol oxidase, subunit I & $-2,7$ & $0,00^{*}$ \\
\hline AFE_063I & cyoA & cytochrome o ubiquinol oxidase, subunit II & $-3,2$ & $0,00^{*}$ \\
\hline
\end{tabular}

Sulfate adenylyltransferase

\begin{tabular}{|c|c|c|c|c|c|}
\hline AFE_0539 & sat & sulfate adenylyltransferase, putative/adenylylsulfate kinase & 0,7 & $0,00 *$ & \\
\hline \multicolumn{6}{|c|}{ Thiosulfate-quinone oxidoreductase complex operon } \\
\hline AFE_0046 & & conserved hypothetical protein & $-1,7$ & $0,00 *$ & \\
\hline AFE_0045 & & sulfur/pyrite/thiosulfate/sulfide-induced protein & $-1,1$ & $0,00 *$ & $\begin{array}{l}\text { ATCC } 19859 /[25] \\
\text { ATCC } 19859 /[28]\end{array}$ \\
\hline AFE_0044 & $\operatorname{doxDA}$ & $\begin{array}{l}\text { Thiosulfate-quinone oxidoreductase, DoxD-like family } \\
\text { protein }\end{array}$ & $-2,3$ & $0,00 *$ & \\
\hline AFE_0043 & & periplasmic solute-binding protein, putative & $-2,2$ & $0,00 *$ & $\begin{array}{l}\text { CCM 4253/[24] } \\
\text { ATCC } 23270 /[25] \\
\text { ATCC } 23270 /[29]\end{array}$ \\
\hline AFE_0042 & & Tat pathway signal sequence domain protein & $-1,5$ & $0,00 *$ & \\
\hline AFE_004I & & C4-dicarboxylate transporter/malic acid transport protein & $-1,5$ & $0,00 *$ & \\
\hline
\end{tabular}

Tetrathionate hydrolase

\begin{tabular}{llllll}
\hline AFE_0029 $\quad$ tetH $\quad$ Tetrathionate hydrolase & $-0,6$ & $0,22 *$ & ATCC 23270/[27]
\end{tabular}

Gene expression values ( $\log _{2}$ ratio of median) for all genes/operons alluded in the revised model of sulfur oxidation in A. ferrooxidans ATCC 23270 . Genes with a $\log _{2}$ ratio of median larger than $|1.5|$ (corresponding to genes induced more than 2.8 fold) are considered differentially expressed (indicated with *) and genes p-value $<0,005$ are considered significant. Gene ID is that of Genbank genome annotation NC 01176 I. The reference and the strain in which the level of the gene product has been shown to be higher in $\mathrm{S}^{0}$ than in $\mathrm{Fe}$ (II) conditions are indicated in the last column.

of intracellular protons requires a concomitant increase in intracellular electrons for their neutralization, so as not to compromise the internal $\mathrm{pH}$ of the cell. These electrons could come from the downhill pathway during Fe(II) oxidation as shown in Figure 1.

The organization and regulation of the components of $\mathrm{Fe}(\mathrm{II})$ oxidation in A. ferrooxidans appear to be unique to this organism, although Thiobacillus prosperus strain V6 possesses a transcriptional unit upregulated in iron conditions with some similarity to the rus operon [44]. However, the $T$. prosperus operon lacks the cyc1 and the rus genes encoding cytochrome $c_{4}$ and rusticyanin, respectively. The latter is located downstream from the cluster, is monocistonic and is expressed in iron and sulfur growth conditions [44], suggesting different regulatory mechanisms compared to A. ferrooxidans. In Leptospirillum group II, the electron transfer chain involved in $\mathrm{Fe}(\mathrm{II})$ oxidation contains two cytochromes $c$ and a $c b b_{3}$ cytochrome oxidase [45-47] but no blue copper protein such as rusticyanin. In the archaea Ferroplasma acidarmanus a blue copper protein (sulfocyanin) has been suggested to transfer the electrons from $\mathrm{Fe}$ (II) to a $c b b_{3}$-type terminal oxidase [48]. While the genes encoding four blue copper proteins (two sulfocyanin-like and two rusticyanin-like) have been identified in Metallosphaera sedula [49], none of them respond to the presence of iron in the medium [50]. However, foxA (cytochrome oxidase subunit I) and soxNL (cytochrome $b$ and [2Fe-2S] Rieske) -cbs $A B$ (cytochromes b) clusters have been predicted to be important for $\mathrm{Fe}$ (II) oxidation in M. sedula. Genes encoding cytochrome $c$ oxidase subunits I and II ( foxAB) and CbsA-like cytochrome $b(f o x C)$ have been also proposed to be involved in iron oxidation in Sulfolobus metallicus [51]. It appears therefore that different pathways for ferrous iron oxidation have evolved in prokaryotes.

\section{Extending the current model of the oxidation of reduced inorganic sulfur compounds (RISCs)}

Predicted genes, proteins or enzymatic activities previously identified in the oxidation of RISCs in different species of A. ferrooxidans include: sqr (AFE_1792) encoding 
Table 3: Q-PCR expression data for relevant validated genes

\begin{tabular}{|c|c|c|c|c|c|}
\hline ID NCOII76I & $\begin{array}{l}\text { Gene } \\
\text { (locus) }\end{array}$ & Function & $\log _{2}(\mathrm{Fe} / \mathrm{S})$ & Induced & $\begin{array}{l}\text { Proteomic data: strain/ } \\
\text { references }\end{array}$ \\
\hline \multicolumn{6}{|l|}{ rus operon } \\
\hline AFE_3I46 & rus & rusticyanin & 3,8 & $\mathrm{Fe}$ & $\begin{array}{l}\text { ATCC } 33020 /[7] \\
\text { CCM } 4253 /[24] \\
\text { ATCC } 19859 /[25]\end{array}$ \\
\hline AFE_3I5I & cup & conserved hypothetical protein & 4,9 & $\mathrm{Fe}$ & ATCC $33020 /[7]$ \\
\hline \multicolumn{6}{|c|}{ Cytochrome c oxidase complex biogenesis operon } \\
\hline AFE_3I4I & ctaR & $\begin{array}{l}\text { iron responsive regulator of the Rrf2 } \\
\text { family }\end{array}$ & 3,9 & $\mathrm{Fe}$ & \\
\hline \multicolumn{6}{|c|}{ Sensor/regulator two-component signal transduction system } \\
\hline AFE_3137 & regA & DNA-binding response regulator & 4,3 & $\mathrm{Fe}$ & \\
\hline \multicolumn{6}{|l|}{ petl operon } \\
\hline AFE_3108 & sdrAl & $\begin{array}{l}\text { oxidoreductase, short-chain } \\
\text { dehydrogenase/reductase family }\end{array}$ & 3,7 & $\mathrm{Fe}$ & \\
\hline AFE_3109 & petAl & $\begin{array}{l}\text { ubiquinol-cytochrome } c \text { reductase, iron- } \\
\text { sulfur subunit }\end{array}$ & 6,4 & $\mathrm{Fe}$ & CCM 4252/[24] \\
\hline AFE_31IO & petBI & $\begin{array}{l}\text { ubiquinol-cytochrome } c \text { reductase, } \\
\text { cytochrome } b \text { subunit }\end{array}$ & 5,7 & $\mathrm{Fe}$ & \\
\hline AFE_3III & petCl & $\begin{array}{l}\text { ubiquinol-cytochrome } \mathrm{c} \text { reductase, } \\
\text { cytochrome } \mathrm{cl} \text { subunit }\end{array}$ & 5,5 & $\mathrm{Fe}$ & \\
\hline
\end{tabular}

\section{Others}

\begin{tabular}{llllll}
\hline AFE_2599 & - & 1,2 & $\mathrm{Fe}$ & \\
\hline AFE_3116 & - & 1,2 & $\mathrm{Fe}$ & \\
\hline AFE_3119 & - & & 3,4 & $\mathrm{Fe}$ & \\
\hline AFE_3124 & cysD & sulfate adenylyltransferase, small subunit & 4,8 & $\mathrm{Fe}$ & CCM 4253/[24]
\end{tabular}

Thiosulfate-quinone oxidoreductase complex operon

\begin{tabular}{|c|c|c|c|c|c|}
\hline AFE_0043 & - & $\begin{array}{l}\text { periplasmic solute-binding protein, } \\
\text { putative }\end{array}$ & $-2,5$ & $S$ & $\begin{array}{l}\text { CCM 4253/[24] } \\
\text { ATCC 19859/[25] } \\
\text { ATCC 23270/[29] }\end{array}$ \\
\hline AFE_0045 & - & $\begin{array}{l}\text { sulfur/pyrite/thiosulfate/sulfide-induced } \\
\text { protein }\end{array}$ & $-1,2$ & $S$ & $\begin{array}{l}\text { ATCC } 19859 /[25] \\
\text { ATCC } 19859 /[28]\end{array}$ \\
\hline
\end{tabular}

\section{Cytochrome bd ubiquinol oxidase}

\begin{tabular}{llll}
\hline AFE_0955 cydA cytochrome d ubiquinol oxidase, subunit I & $-2,0$ & $\mathrm{~S}$
\end{tabular}


Table 3: Q-PCR expression data for relevant validated genes (Continued)

\section{Cytochrome bo3 ubiquinol oxidase}

AFE_0632 cyoB cytochrome o ubiquinol oxidase, subunit I $\quad-3,2 \quad S$

\section{Heterodisulfide reductase complex operon}

\begin{tabular}{llllll}
\hline AFE_2553 & hdrA & $\begin{array}{l}\text { Pyridine nucleotide-disulfide } \\
\text { oxidoreductase }\end{array}$ & $-1,3$ & $\mathrm{~S}$ \\
\hline AFE_2555 & hdrC & iron-sulfur cluster-binding protein & $-1,6$ & $\mathrm{~S}$ \\
\hline AFE_2586 & hdrB & $\begin{array}{l}\text { heterodisulfide reductase subunit B, } \\
\text { homolog }\end{array}$ & $-0,8$ & $\mathrm{~S}$ \\
\hline
\end{tabular}

\section{Sulfide-quinone reductase}

\begin{tabular}{|c|c|c|c|c|c|}
\hline AFE_I 792 & sqr & Sulfide-quinone reductase & $-0,1$ & $\approx$ & $\begin{array}{l}\text { CCM 4253/[24] } \\
\text { NASF-I/[26] }\end{array}$ \\
\hline
\end{tabular}

\section{Others}

\begin{tabular}{|c|c|c|c|c|c|}
\hline AFE_0049 & - & $\begin{array}{l}\text { periplasmic solute-binding protein, } \\
\text { putative }\end{array}$ & 0,3 & $\approx$ & ATCC 23270/[29] \\
\hline AFE_I663 & $g / c F$ & glycolate oxidase, iron-sulfur subunit & $-1,7$ & $\mathrm{~S}$ & \\
\hline AFE_I677 & cbbOla & $\begin{array}{l}\text { von Willebrand factor type A domain } \\
\text { protein }\end{array}$ & $-1,9$ & $S$ & \\
\hline AFE_297I & cysN2 & sulfate adenylyltransferase, large subunit & $-1,3$ & $S$ & \\
\hline AFE_0282 & fur & ferric uptake regulator & 0,6 & $\approx$ & \\
\hline AFE_2324 & pgm & phosphoglucomutase & 0,6 & $\approx$ & \\
\hline AFE_0445 & galU & $\begin{array}{l}\text { UTP-glucose-I-phosphate } \\
\text { uridylyltransferase }\end{array}$ & 0,2 & $\approx$ & \\
\hline AFE_I342 & epsS & UDP-glucose 4-epimerase & 0,0 & $\approx$ & \\
\hline AFE_2840 & malQ & glycosyl hydrolase & $-0,2$ & $\approx$ & \\
\hline AFE_2836 & $g \mid b B$ & I,4-alpha-glucan branching enzyme & $-0,6$ & $\approx$ & \\
\hline AFE_3054 & $c b b O l b$ & $\begin{array}{l}\text { von Willebrand factor type A domain } \\
\text { protein }\end{array}$ & $-0,1$ & $\approx$ & \\
\hline AFE_2I57 & $c b b O l l$ & $\begin{array}{l}\text { von Willebrand factor type A domain } \\
\text { protein }\end{array}$ & $-0,6$ & $\approx$ & \\
\hline AFE_0539 & cysN3 & sulfate adenylyltransferase, large subunit & 0,1 & $\approx$ & \\
\hline AFE_2602 & - & hypothetical & $-0,1$ & $\approx$ & ATCC 19859/[25] \\
\hline
\end{tabular}

Real time PCR gene expression values ( $\log _{2}$ ratio of median) for relevant genes alluded in the revised iron or sulfur oxidation models for $A$. ferrooxidans ATCC 23270. Genes with a $\log _{2}$ ratio of median larger than |I.5| (corresponding to genes induced more than 2.8 fold) are considered differentially expressed (indicated with *). Gene ID is that of Genbank genome annotation NC 0II76I. The reference and the strain in which the level of the gene product has been shown to be higher in one of the conditions tested ( $\mathrm{Fe}(\mathrm{II})$ or $\mathrm{S}^{0}$ ) are indicated in the last column. 
sulfide quinone reductase from NASF-1 strain [26,52], doxDA (AFE_0044) encoding thiosulfate quinone oxidoreductase from ATCC23270 [53] and from the CCM4253 strain [54], tetH (AFE_0029) encoding tetrathionate hydrolase from ATCC23270 [27], cydAB (AFE_0955-0954) encoding a $b d$ oxidase and $c y o A B C D$ (AFE_0631-0634) encoding a $b o_{3}$ oxidase from ATCC19859 [11] (See Figure 2). All these genes are upregulated in sulfur-containing media relatively to $\mathrm{Fe}(\mathrm{II})$ (Table 2[24-29] and Table 3[7,24-26,28,29]). This is also the case for the petII operon (AFE_2727-2732) encoding a second $b c_{1}$ complex, a cytochrome $c_{4}$, SdrA2 and a high potential iron-sulfur protein, Hip, as already reported for ATCC19859 [11], ATCC33020 [13] and ATCC23270 [14] strains (Table 2[24-29] and Table 3[7,24-26,28,29]). This second $b c_{1}$ complex has been proposed to function directly transferring electrons from sulfur to oxygen (Figure 2), and possibly in the aerobic and anaerobic oxidation of sulfur and formate described by Pronk et al. [55]. In that case, the $b c_{1}$ complex receives the electrons from the quinol pool and transfers them to the membranebound cytochrome $c_{4}$ CycA2 and/or to the periplasmic high potential iron-sulfur protein Hip that subsequently gives the electrons to the terminal oxidase $[2,13,14]$ (Figure 2). SdrA2, like SdrA1 (see above), may promote electron flow from the quinone pool to the NADH complex (Figure 2). These findings support earlier models of the branched electron transfer flow during $S^{0}$ oxidation $[2,11,13,14]$ (Figure 2). However, this model is far from being complete and several outstanding questions remain unanswered, including the identification of the enzymes that oxidize sulfur and sulfite.

\section{Sulfur}

Seven genes, potentially encoding a heterodisulfide reductase complex HdrABC (AFE_2586 and AFE_25552550) were highly upregulated in cells grown in sulfur medium (Table 2[24-29] and Table 3[7,24-26,28,29]). This complex catalyzes the reversible reduction of the disulfide bond X-S-S-X coupled with energy conservation in methanogenic archaea ([56] and references therein) and sulfate reducing archaea and bacteria [57]. This complex in A. ferrooxidans is predicted to have three different cytoplasmic HdrB subunits (AFE_2586, 2554 and 2550) with the cysteine-rich domain which binds the unusual type [4Fe-4S] cluster [58], involved in disulfide reduction $[56,59]$. In addition, genes potentially encoding the ferredoxin-like and the flavoprotein subunits, $\mathrm{HdrC}$ (AFE_2555 and 2551) and HdrA (AFE_2553) are present in the same locus. The flavoprotein HdrA subunit exhibits a possible $\mathrm{N}$-terminal membrane spanning region, a conserved FAD binding site (GXGXXGX $\left.{ }_{16-19}(\mathrm{D} / \mathrm{E})\right)$, and the conserved four cysteine cluster $\left(\mathrm{CXGXRDX}_{6-8} \mathrm{CSX}_{2} \mathrm{CC}\right)$ that binds a Fe-S center, typical of the cytoplasmic ironsulfur flavoprotein type enzyme.
Three genes encoding for sulfur metabolism accessory proteins, placed immediately upstream of the heterodisulfide reductase complex, are similarly upregulated (Table 2[24-29]). These encode a cytoplasmic rhodanaserelated sulfurtransferase (AFE_2558, COG0607) [60], a cytoplasmic SirA-like disulfide bond formation regulator (AFE_2557, pfam01206, COG0425, IPR001455) and an inner membrane located peroxiredoxin of the DrsE superfamily (AFE_2556, COG2210 and 2044). The rhodanase AFE_2558 is $48 \%$ similar to the Sud protein from Wolinella succinogenes which binds and transfers polysulfide sulfur to the polysulfide reductase located in the cytoplasmic membrane $[61,62]$. In turn, the SirA-like protein AFE_2557 is 54\% similar to the TusA protein from Vibrio fischeri and other bacteria which belong to a complex sulfur-relay system that facilitates specific sulfur flow/ trafficking from various pathways [63-65]. Finally, DsrE family proteins such as that predicted to be encoded by AFE_2556 are small proteins recently shown to be involved in sulfur transfer reactions during sulfur oxidation [66].

Significant sequence similarity and conserved gene organization of the A. ferrooxidans heterodisulfide reductase complex and accessory proteins is restricted only to Aquifex aeolicus and known acidophilic sulfur oxidizing microorganisms Hydrogenobaculum sp. Y04AAS1, Hydrogenivirga sp. 128-5-R1-1, Metallosphaera sedula [50], Sulfolobus acidocaldarius, S. tokodaii and S. solfataricus (Figure 3 ), associating the whole gene cluster with sulfur oxidation. In methanogenic and sulfate reducing archaea, HdrA receives the electrons from the hydrogenase and transfers them through $\mathrm{HdrC}$ to the heterodisulfide reductase catalytic site located in HdrB. Accompanying the reduction of heterodisulfide, protons are extruded across the membrane creating a proton motive force. We hypothesize that in A. ferrooxidans and the sulfur oxidizers referred above, the Hdr complex, driven by the naturally existing proton gradient, could be working in reverse and oxidizing disulfide intermediaries (from sulfur oxidation) to sulfite and delivering the collected electrons to the membrane quinol pool (Figure 2). In addition, the three accessory sulfurtransferases are likely involved in the transfer of the proposed sulfane sulfur $[67,68]$ to the heterodisulfide reductase (Figure 2).

The predicted A. ferrooxidans heterodisulfide reductase complex has additional features that are consistent with its proposed role in RISCs oxidation. Sulfur oxidation in a variety of different $A$. ferrooxidans strains has been shown to require glutathione $[67,68]$ and requires a neutral $\mathrm{pH}$ optimum [67], suggesting a cytoplasmic activity in agreement with the predicted localization of the heterodisulfide reductase catalytic site (Figure 2). Second, nonheme iron and labile sulfur have been shown to be 


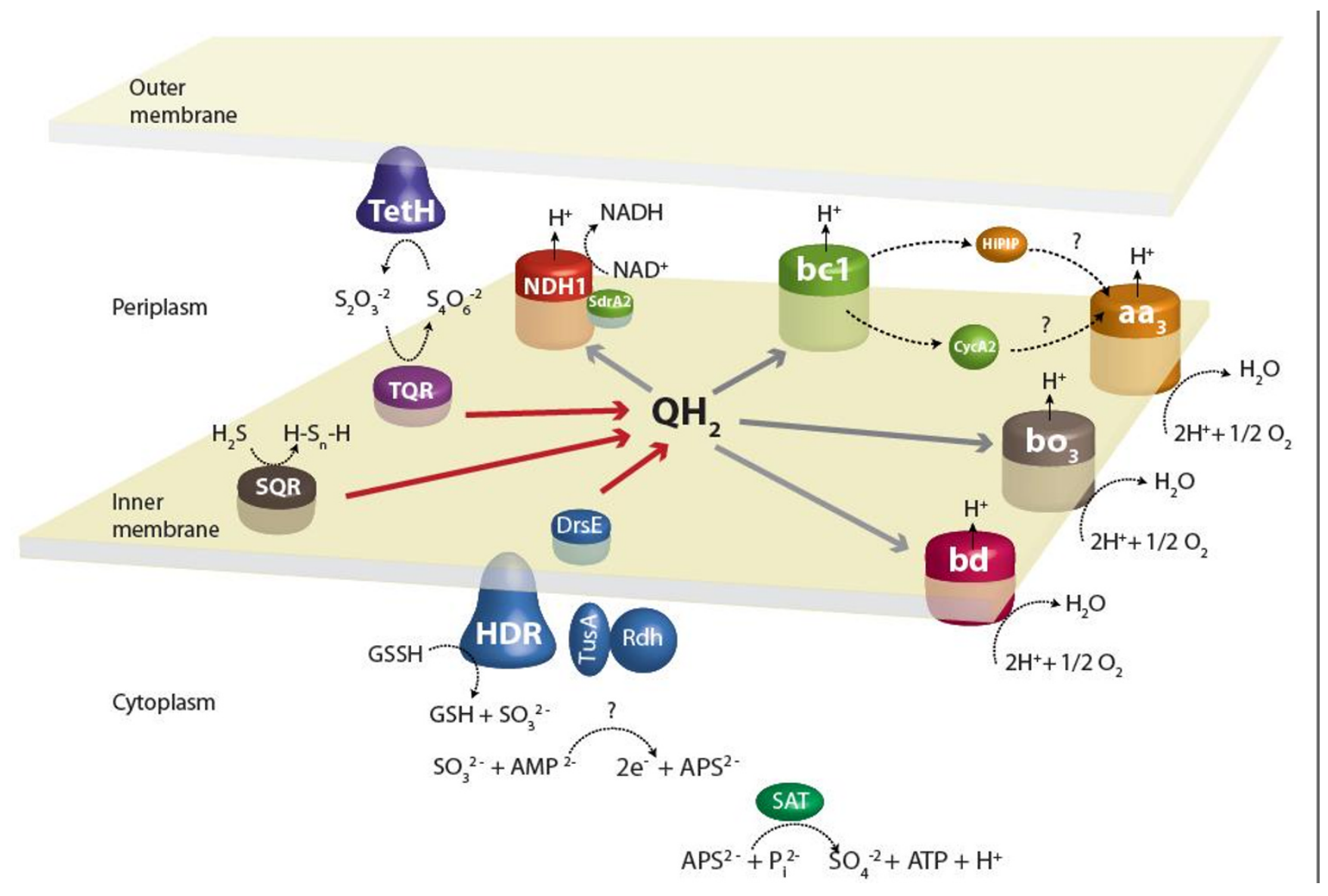

\section{Figure 2}

Model of sulfur oxidation in A. ferrooxidans ATCC 23270. Reduced inorganic sulfur compound (RISC) oxidation pathways are predicted to involve various enzymes, enzyme complexes and a number of electron carriers located in different cellular compartments: in the outer membrane facing the periplasm (tetrathionate reductase, TetH), in the periplasm (high potential iron-sulfur protein, HiPIP), attached to the cytoplasmic membrane on the periplasmic side (cytochrome c, CycA2), in the cytoplasmic membrane (sulfide quinone reductase (SQR), thiosulfate quinone reductase (TQR), bc, complex, NADH complex I, bd and $\mathrm{bo}_{3}$ terminal oxidases) and in the cytoplasm (heterodisulfide reductase (HDR), and ATP sulfurylase (SAT)). Insoluble sulfur is first converted to sulfane sulfate (GSSH) which is then transferred to the heterodisulfide reductase (HDR) through a cascade of sulfur transferases (DsrE, TusA and Rhd). Electrons coming from sulfide $\left(\mathrm{H}_{2} \mathrm{~S}\right)$, thiosulfate $\left(\mathrm{S}_{2} \mathrm{O}_{3}{ }^{2-}\right)$ or sulfane sulfate $(\mathrm{GSSH})$ are transferred via the quinol pool $\left(\mathrm{QH}_{2}\right)$ either $(\mathrm{I})$ directly to terminal oxidases bd or $b_{3}$, or indirectly throught a $b c_{1}$ complex and a cytochrome $c(\mathrm{CycA} 2)$ or a high potential iron-sulfur protein (HiPIP) probably to the $a a_{3}$ oxidase where $\mathrm{O}_{2}$ reduction takes place or (2) to NADH complex I to generate reducing power.

present in a sulfur oxidizing enzyme preparation of $A$. ferrooxidans [67] and iron-sulfur clusters are predicted to be present in the A. ferrooxidans $\mathrm{HdrB}$ and C subunits. Third, sulfur oxidation has been shown to be inhibited by HQNO in A. ferrooxidans [69], in agreement with the proposal that the quinone pool is the physiological electron acceptor (Figure 2). Fourth, the actual substrate of the sulfur oxidizing enzyme in A. ferrooxidans is thought not to be elemental sulfur, which has poor water solubility and cannot enter the cell, but rather sulfane sulfur of $\mathrm{GS}_{\mathrm{n}} \mathrm{H}$ species $(n>1)$ and most likely GSSH $[67,68]$. Sulfane sulfate would thus provide the necessary disulfide bond X-S$\mathrm{S}$-X to serve as a substrate for the predicted catalytic activ- ity of the A. ferrooxidans heterodisulfide reductase (Figure 2 ). Conserved within the heterodisufide reductase gene cluster, between $h d r A$ and $h d r C 2$, is a putative gene of unknown function (AFE_2552) whose product is predicted to reside in the cytoplasm (Figure 2). Given its conserved gene context, we propose that it is also involved in RISCs oxidation and it is now pinpointed for experimental investigation.

\section{Sulfite}

Another step in the sulfur oxidation model that awaits genetic characterization is sulfite oxidation. Being metastable and considered short-lived in mine waste environ- 


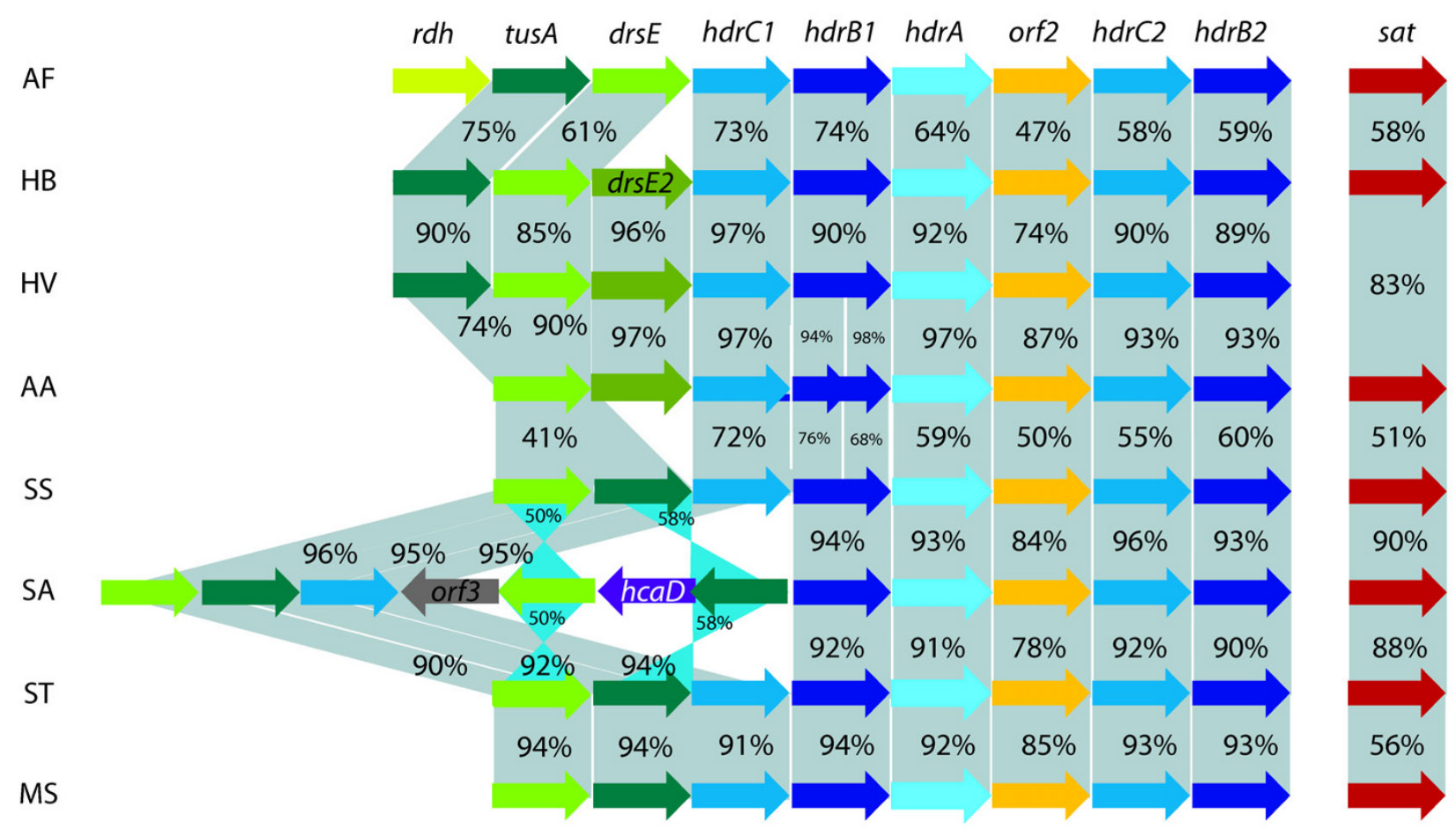

\section{Figure 3}

Comparison of the hdr cluster between A. ferrooxidans ATCC 23270 and other sulfur oxidizers. Heterodisulfide reductase complex $\left(\mathrm{HdrC} \mathrm{B}_{1} \mathrm{AOrf} 2 \mathrm{HdrC} \mathrm{B}_{2}\right)$, accessory proteins (Rhd, TusA, DsrE) and ATP sulfurylase (Sat) in AF: A. ferrooxidans ATCC 23270 (NC_0I I206), AA: Aquifex aeolicus (NC_000918) and known acidophilic sulfur oxidizing microorganisms HB: Hydrogenobaculum sp. Y04AASI (NC_0I I I26), HV: Hydrogenivirga sp. I28-5-RI-I (NZ_ABHJ00000000), MS: Metallosphaera sedula (NC_009440), SA: Sulfolobus acidocaldarius (NC_007I8I), ST: S. tokodaii (NC_003I06) and SS: S. solfataricus (NC_002754). Percentage of amino-acid similarity is indicated. Blue triangles represent inversion in the gene order.

ments, one possibility is that sulfite rapidly oxidizes nonenzymically to sulfate, thiosulfate or glutathione S-sulfonate in the presence of $\mathrm{Fe}(\mathrm{III})[70,71]$ or sulfur [72]. However, the involvement of a protein catalyzing this reaction is more likely since a sulfite oxidase activity was purified from three different strains of A. ferrooxidans, namely TM [73], ATCC13661 [74] and AP19-3 [75,76]

Genes coding for known periplasmic enzymes involved in the direct oxidation of sulfite during sulfur dissimilatory metabolism (sor $A B$ or sox $C D$ [77]) have not been detected in the A. ferrooxidans genome. In our model (Figure 2), sulfite is hypothesized to be produced in the cytoplasm by heterodisulfide reductase. Therefore, subsequent oxidation of sulfite is likely to occur in this cellular location and therefore would not be expected to proceed via the classical periplasmic Sor or Sox. One possibility for the cytoplasmic activity is that sulfite is converted to adenosine-5'phosphosulfate (APS) via the well characterized APS reductase complex encoded by aprBA [78-80]. However, the genome contains no candidates with significant similarity to aprBA, although it does have a predicted sat
(AFE_0539) which, in other microorganisms, encodes an ATP sulfurylase responsible for the second step in this pathway. The A. ferrooxidans Sat shares $44 \%$ identity and $60 \%$ similarity with both domains of the bifunctional SAT/APS kinase from Aquifex aeolicus that catalyzes the production of ATP and sulfate from APS and pyrophosphate $[81,82]$. If Sat is indeed catalyzing APS to sulfate (Figure 2), an enzyme catalyzing the oxidation of sulfite to APS is required. This missing function could be accomplished by the conserved hypothetical gene embedded in the $h d r$ locus of sulfur oxidizers (Figure 3 ). The concordance of gene occurrence and organization between $A$. aeolicus, Hydrogenobaculum sp. Y04AAS1 the Sulfolobales and $A$. ferrooxidans including 1 ) the $h d r$ locus with a gene of unknown function 2) sat and 3) a lack of aprBA, strongly suggests that these microorganisms have a novel sulfur oxidation pathway.

Our data agree with the model proposed for $\mathrm{S}^{0}$ oxidation in M. sedula, including a heterodisulfide reductase ( $h d r)$, a tetrathionate hydrolase (tet $H$ ), a terminal oxidase complex based on both quinol oxidase (soxCL) and $a a_{3}$-type 
cytochrome oxidase (soxAB) components [50]. In S. metallicus, a gene (sor), encoding sulfur oxygenase reductase, which is absent in A. ferrooxidans, is the dominant transcript in sulfur-grown cells and is therefore proposed to be involved in sulfur oxidation [51]. In conclusion, the RISCs oxidation pathways of acidophiles are not only different from those of neutrophilic sulfur oxidizers $[17,18]$ but also appear to be different among the acidophilic sulfur-oxidizers including between members of the Acidithiobacillus genus [83]. In that sense, the conservation of the $h d r$ locus in different acidophilic sulfur oxidizers, archaea and eubacteria, is noteworthy and merits further investigation.

\section{Additional Discussion}

Genomic and transcriptomic (microarrays and real-time quantitative PCR) studies of iron and sulfur energetic metabolism of $A$. ferrooxidans, not only confirm previous data, but elaborate on the complexity of these pathways. Both iron and RISCs respiratory chains are branched and redundant $[2,11,13,14]$ (Figures 1 and 2). This provides A. ferrooxidans with a flexible respiratory system that may allow it to adapt efficiently to environmental changes by modulating gene expression according to the growth conditions (substrate, oxygen concentration, growth phase, etc.). Another way to adapt efficiently to a change in the growth conditions is by modifying the association of complexes as suggested recently for iron respiration in $A$. ferrooxidans [15]. In the case of the cytochrome $c$ oxidase complex of Dictyostelium discoideum, the oxygen concentration induces a switch between two interchangeable subunit isoforms of the cytochrome $c$ oxidase [84-86]. This switch has been shown to be due to transcriptional regulation and also to different stabilities of the two subunits toward oxygen [86].

Both iron and RISCs oxidation pathways involve outer membrane, periplasmic and inner membrane components (Figures 1 and 2). According to our hypothesis, several super-complexes spanning the outer and/or the inner membranes are expected to conduct either the electrons to the oxygen, or the sulfane-sulfur to the catalytic side of the herodisulfide reductase, from pyrite $\left(\mathrm{FeS}_{2}\right)$, which is a natural substrate of $A$. ferrooxidans. While such a super-complex has been isolated recently for iron oxidation [15], no biochemical data are available until now to substantiate the existence of a sulfane-sulfur transfer supramolecular structure. While a sulfurtransferase complex encoded by the $h d r$ locus is likely to be involved in the transfer of the proposed sulfane sulfur to the heterodisulfide reductase from the inner membrane to the cytoplasm (Figure 2), expression data suggests no obvious upregulated outer membrane protein as proposed by Rohwerder and Sand [68] to allow it to cross the cell wall. We propose also the existence of a cytoplasmic super-complex catalyzing both the oxidation of sulfane-sulfur to sulfite and of sulfite to APS, preventing the accumulation of sulfite in the cytoplasm (Figure 2). While the existence of such a complex has not been demonstrated in A. ferrooxidans, a thiosulfate-oxidizing system oxidizing hydrogen sulfide, thiosulfate, sulfur and sulfite directly to sulfate without the presence of free intermediates has been evidenced in Paracoccus versutus and Paracoccus pantotrophus $([17,87]$ and references therein). Moreover, the methanogenic and sulfate reducing archaea heterodisulfide reductase forms a tight complex with the hydrogenase, which catalyzes its reduction with $\mathrm{H}_{2}([56,57]$ and references therein). Such supramolecular structures will allow (1) stabilization of the different components (2) electron, or sulfane sulfur, channeling leading to more efficient transfer, and (3) diffusion avoidance preventing toxic compound leakage.

\section{Conclusion}

- Bioinformatic analysis coupled with gene transcript profiling extends our understanding of the iron and reduced inorganic sulfur compounds oxidation pathways in A. ferrooxidans.

- Novel genes predicted to be involved in iron oxidation (Figure 1) include those potentially encoding: i) heme biosynthesis and insertion into the terminal electron acceptor cytochrome $a a_{3}$ oxidase used in the downhill flow of electrons from $\mathrm{Fe}(\mathrm{II})$ to reduce oxygen to water, ii) subunits of the $\mathrm{F}_{\mathrm{o}}$ ATP synthetase that may be an adaptation to extremely low pHs encountered during iron oxidation, iii) a copper-containing protein that may be involved in electron transfer or in copper insertion, iv) two subunits and one predicted accessory protein of the NADH complex that may promote the flow of electrons from the quinone pool to the NADH complex during uphill electron flow and v) two potential regulators of alternate electron pathways predicted to respond to iron and the status of the quinone pool respectively.

- Novel genes predicted to be involved in RISCs oxidation (Figure 2) include those potentially encoding: i) three sulfurtransferases, ii) a heterodisulfide reductase complex, iii) an ATP sulfurylase and iv) a NADH complex accessory protein that may promote uphill electron flow from the quinone pool to the NADH complex during RISCs oxidation.

- The models (Figures 1 and 2) provide unified and coherent descriptions of iron and RISCs oxidation and suggests mechanisms for their regulation within the type strain, eliminating previous confusion caused by models built from analyses of multiple and divergent strains of this microorganism. 
- The identification of differentially expressed genes of unknown function predicted to be involved in iron and RISCs oxidation direct the experimental biologist to future research.

\section{Methods \\ Strains and culture conditions}

A. ferrooxidans type strain ATCC 23270 was obtained from the American Type Culture Collection. A. ferrooxidans was grown at $30^{\circ} \mathrm{C}$ under oxic conditions with $200 \mathrm{rpm}$ agitation in (i) $\mathrm{Fe}(\mathrm{II})$-medium $\left(62 \mathrm{mM} \mathrm{FeSO}_{4}-7 \mathrm{H}_{2} \mathrm{O}\right.$ in basal salts solution $\left(\left(\mathrm{NH}_{4}\right)_{2} \mathrm{SO}_{4}: 0.4 \mathrm{~g}\right.$. L ${ }^{-1}, \mathrm{~K}_{2} \mathrm{HPO}_{4}: 0.4 \mathrm{~g} . \mathrm{L}^{-1}$, $\mathrm{MgSO}_{4}-7 \mathrm{H}_{2} \mathrm{O}: 0.4 \mathrm{~g}$. L $\mathrm{L}^{-1}$ adjusted to $\mathrm{pH} 1.6$ with $\mathrm{H}_{2} \mathrm{SO}_{4}$ or (ii) $\mathrm{S}^{0}$-medium $(1 \%(\mathrm{w} / \mathrm{v})$ elemental sulfur in basal salts solution $\left(\left(\mathrm{NH}_{4}\right)_{2} \mathrm{SO}_{4}: 0.4\right.$ g. L $\mathrm{L}^{-1}, \mathrm{~K}_{2} \mathrm{HPO}_{4}: 0.4$ g. L L $\mathrm{MgSO}_{4}-7 \mathrm{H}_{2} \mathrm{O}: 0.4$ g. $\mathrm{L}^{-1}$ adjusted to $\mathrm{pH} 3.5$ with $\mathrm{H}_{2} \mathrm{SO}_{4}$ ). When reaching mid-logarithmic phase cells were harvested by centrifugation at $4^{\circ} \mathrm{C}$ and washed with basal salt solution ( $\mathrm{pH}$ adjusted). To remove iron traces or sulfur particles before further treatment several cycles of washing and 1 minute low speed spin-centrifugations were performed. Clean cell pellets were frozen in liquid nitrogen and stored at $-80^{\circ} \mathrm{C}$ until used for RNA extraction.

\section{RNA isolation}

Total RNA was extracted using a modified acid-phenol extraction method [88], including a preliminary TRIZOL ${ }^{\circledR}$ reagent (Invitrogen) extraction step. This RNA was used directly for cDNA synthesis and labeling. For real-time PCR, RNAs were additionally purified with the High Pure RNA isolation kit (Roche Applied Biosystem) and treated twice with DNAse I (Roche Applied Biosystem). The lack of DNA contamination was checked by PCR on each RNA sample.

\section{Microarray production}

A. ferrooxidans ATCC 23270 oligonucleotide microarrays were designed and produced in-house. Internal 50-mers targeting each of the 3037 putative ORFs predicted in the genomic sequence of $A$. ferrooxidans ATCC 23270 (TIGR release September $2003 ; 2.98 \mathrm{Mb}$ ) were selected using the Oligoarray software (Version 1.0), synthesized by MWG Biotech and spotted in duplicate on Gamma Amino Propyl Silane Corning UltraGAPS slides, according to the manufacturer's instructions, with a ChipWriterProarrayer (Bio-Rad, 1000 Alfred Nobel Drive Hercules, CA) at the Marseille-Nice Genopole (France). A special set of control oligonucleotides (negative, positive, tiled and antisense sequences) was included to evaluate probe specificity and adjust the hybridization conditions. 50-mer oligonucleotides corresponding to the CDS of the gfp gene from Aequorea sp. (L29345), the rad9 gene form Saccharomyces cereviciae (M26049) and the idi2 gene from human (AK303669) were used as negative controls. The array design and spotting protocol were deposited in ArrayEx- press database [89] under the accession codes A-MEXP1478 and A-MEXP-1479.

\section{Microarray experimental design}

This experiment consisted of 8 independent hybridizations using total RNA obtained from 2 different iron(FeIIA and FeIIB) and 2 different sulfur-replicate cultures $\left(\mathrm{S}^{\circ} \mathrm{A}\right.$ and $\left.\mathrm{S}^{\circ} \mathrm{B}\right)$. Each RNA sample was labeled once with each dye (e.g. $S^{0}$ A_Cy ${ }^{\circledR}$ and $S^{0}$ A_Cy ${ }^{\circledR} 3$ ) and hybridized against a reciprocally labeled cDNA sample (e.g. FeIIA_Cy ${ }^{\circledR} 3$ and FeIIA_Cy ${ }^{\circledR}$ ). The cDNAs obtained for each biological replicate (e.i. A or B) were cohybridized against two different types of microarrays obtained in different spotting campaigns (Oligoarray v.1 or Oligoarray v.2). More details of the experimental design are available in the ArrayExpress database under the accession code EMEXP-1990.

\section{Labeling and hybridization}

The ChipShot ${ }^{\mathrm{TM}}$ Labeling Clean-Up System (PromegaCorning) was used to generate fluorescently labeled cDNA via direct incorporation of $\mathrm{Cy}^{\circledR} 3$ and $\mathrm{Cy}^{\circledR} 5$-labeled nucleotides (Amersham Biosciences). The reverse transcription reaction was performed in the presence of $5 \mu \mathrm{g}$ total RNA and random hexamers according to manufacturer's recommendations. Two independent cDNA preparations were labeled once with each dye (reverse dye labeling) to account for sampling differences, biases in dye coupling or emission efficiency of $\mathrm{Cy}^{\circledR}$-dyes. Labeled cDNA was purified from contaminating fluorescent dNTPs and degraded RNA using the ChipShot Labeling Clean-Up System (Promega-Corning). Dye incorporation efficiency was determined by absorbance readings at 260, 550 and $650 \mathrm{~nm}$ and the frequency of incorporation (FOI, pmol of dye incorporated per ng of cDNA) was calculated according to Promega's instructions. Optimally labeled samples were combined, vacuum-dried and resuspended to a final volume of $40-50 \mu \mathrm{L}$ in Corning Pronto! Universal Hybridization Buffer. The combined denatured target cDNA samples $\left(95^{\circ} \mathrm{C}\right.$ for $5 \mathrm{~min}$ ) were hybridized to the spotted slides for $14 \mathrm{~h}$ at $42^{\circ} \mathrm{C}$ in the Corning hybridization chamber. Following hybridization, slides were washed in serial dilutions of Corning Wash Buffers as recommended by the manufacturer and dried by centrifugation at $1200 \times g$ for $2 \mathrm{~min}$.

\section{Image acquisition and data analysis}

Microarrays were scanned for the $\mathrm{Cy}^{\circledR} 3$ and $\mathrm{Cy}^{\circledR} 5$ fluorescent signals using the ScanArray 5000 Microarray Analysis System (PerkinElmer Life Sciences, Inc.). Scans stored as 16-bit TIFF (Tagged Information File Format) image files and then analyzed with the image quantification software package GenePix Pro 6.0 (Axon Instruments, Inc.). Saturated and low-quality spots (spots smaller than $60 \mu \mathrm{m}$ or bigger than $160 \mu \mathrm{m}$ in diameter, sub-circular in shape 
and/or exhibiting uneven fluorescence distribution) were flagged and filtered out. Local background was subtracted from the recorded spot intensities and median values for each spot were Log transformed $\left(\log _{2}\right)$ and normalized by average intensity of each slide to account for any difference in total intensity between the scanned images using the Acuity microarray analysis software (Version 4.0, Axon Instrument Inc.). The processed $\mathrm{Fe}(\mathrm{II})$ and $\mathrm{S}^{0}$ signal intensities for each spot were used for calculating the expression ratio $\mathrm{Fe}(\mathrm{II}) / \mathrm{S}^{0}$. Twenty four replicate ratio values per gene, resulting from direct and reverse labeling, replicate spots and replicate experiments, were used for further statistical analysis of the data. The statistical significance of differential expression in $\mathrm{Fe}(\mathrm{II})$ or $\mathrm{S}^{0}$ grown cells, was assessed using Acuity package. The raw data, as well as the processed (filtered and Median normalized) data, for all hybridizations was submitted to the ArrayExpress database and is available under the accession code E-MEXP1990. A 1.5 fold deviations from the 1:1 hybridization ratio was taken as indicative of differential gene expression in the two growth conditions analyzed. Hierarchical cluster analysis (Pearson correlation, average linkage) was performed using Genesis software suit [90]. Functional annotations were retrieved from Valdés et al. [8].

\section{Real-time quantitative PCR}

The relative abundances of a set of differentially expressed genes and a set of invariant genes, according to the microarray results obtained, were determined in $\mathrm{Fe}(\mathrm{II})$ - and $\mathrm{S}^{0}$ grown cells by real-time PCR. Specific primers for the genes of interest amplifying average products of $300 \mathrm{bp}$ with about $50 \mathrm{GC} \%$ and about $55^{\circ} \mathrm{C} \mathrm{Tm}$ were designed (Additional file 3). Equal amounts of A. ferrooxidans DNAseI-treated total RNA were retro-transcribed from these primers with the Superscript $\mathrm{II}^{\mathrm{TM}}$ RNase (Invitrogen Life Technologies) at $42^{\circ} \mathrm{C}$ for $50 \mathrm{~min}$, and then treated at $70^{\circ} \mathrm{C}$ for 15 min to inactivate the enzyme. The real-time PCR quantifications were performed on the cDNA obtained, using the Light-Cycler instrument and the LightCycler Fast Start DNA master (plus) SYBR Green I PCR kit (Roche Applied Biosystems) with external standards as described in Roche Molecular Biochemicals technical note no. LC 11/2000. The real-time PCR experiments were performed twice, with both independent total RNA and cDNA preparations by the comparative threshold cycle method. The calculated threshold cycle $(\mathrm{Ct})$ for each gene was normalized to $\mathrm{Ct}$ of the rrs gene.

\section{Bioinformatic analysis}

The sequence and annotation of the complete A. ferrooxidans strain ATCC 23270 genome was retrieved from GenBank/EMBL/DDBJ (CP001219). Functional assignments for hypothetical and predicted genes of interest were performed manually on a gene-by-gene basis. Amino acid sequences for these genes were used to query the follow- ing databases: National Center for Biotechnology Information (NCBI) nonredundant database, UniProt, TIGRFam, Pfam, PRIAM, KEGG, COG and InterPro. Comparative genomic analyses were performed using the Comprehensive Microbial Resource [91], Microbesonline [92] and String [93].

\section{Authors' contributions}

$\mathrm{DH}$ and EJ conceived the study; CA, RQ, DH and VB designed the experiments; $\mathrm{CA}$ and $\mathrm{RQ}$ carried out the experiments (each contributed equally); YD assisted in the microarray experiments; $C A, R Q, D H$ and VB interpreted the results and wrote the paper. All authors read and approved the paper.

\section{Additional material}

\section{Additional file 1 \\ Differentially expressed genes. Genes with a $\log _{2}$ ratio of median greater than 1.5 (corresponding to genes induced more than 2.8 fold) were con- sidered differentially expressed in the two growth conditions. Functional categories are those defined by the TIGR database [94]. (Quatrini, R., C. Appia-Ayme, Y. Denis, E. Jedlicki, D. S. Holmes and V. Bonnefoy, BMC Genomics). \\ Click here for file \\ [http://www.biomedcentral.com/content/supplementary/1471- 2164-10-394-S1.xls]}

\section{Additional file 2}

Alignment of SdrA with Ndu9 subunit of the NADH complex. The predicted classical NADH binding site in SdrA is highlighted in grey and catalytic residues involved in electron transfer in black. NduA9 and SdrA protein sequences ID in the alignment are as following: human (sp|Q16795|), horse (sp|Q5R5S0|), bovine (sp|P34943|), mouse ( $s p|Q 9 D C 69|)$, Neurospora crassa ( $s p|P 25284|)$, A. ferrooxidans SdrA1 (AFE_3108), A. ferrooxidans SdrA2 (AFE_2728). (Quatrini, R., C. Appia-Ayme, Y. Denis, E. Jedlicki, D. S. Holmes and V. Bonnefoy, BMC Genomics).

Click here for file

[http://www.biomedcentral.com/content/supplementary/14712164-10-394-S2.pdf]

\section{Additional file 3}

Q-PCR primers used in this study. (Quatrini, R., C. Appia-Ayme, Y. Denis, E. Jedlicki, D. S. Holmes and V. Bonnefoy, BMC Genomics). Click here for file

[http://www.biomedcentral.com/content/supplementary/14712164-10-394-S3.pdf]

\section{Acknowledgements}

We thank Jeanine Ratouchniak for technical assistance. We acknowledge the Institut de Pharmacologie Moléculaire et Cellulaire (CNRS, SophiaAntipolis, France) for the oligonucleotides spotting on the slides. Work supported by Fondecyt grants 1050063, I 1060164 and I09045 I, DI-UNAB, 34-06, DI-UNAB I5-06/I, a Microsoft Sponsored Research Award, Ecos/ Conicyt, Geomex and Puces à ADN from the Centre National de la Recherche Scientifique and Biomine European project (sixth PCRD n ${ }^{\circ}$ NM2.ct.2005.500329). We wish to thank A-L. Reysenbach and the Euro- 
pean project partners for their contributions and/or advice to the work presented here.

\section{References}

I. Ingledew WJ: Thiobacillus ferrooxidans. The bioenergetics of an acidophilic chemolithotroph. Biochim Biophys Acta 1982, 683:89-II7.

2. Holmes DS, Bonnefoy V: Genetic and bioinformatic insights into iron and sulfur oxidation mechanisms of bioleaching organisms. In Biomining Edited by: Rawlings DE, Johnson DB. Berlin Heidelberg: Springer-Verlag; 2007:281-307.

3. Appia-Ayme C, Bengrine A, Cavazza C, Giudici-Orticoni MT, Bruschi $M$, Chippaux M, Bonnefoy V: Characterization and expression of the co-transcribed $c y c l$ and $c y c 2$ genes encoding the cytochrome $c_{4}\left(c_{552}\right)$ and a high-molecular-mass cytochrome $c$ from Thiobacillus ferrooxidans ATCC 33020. FEMS Microbiol Lett 1998, 167:171-177.

4. Bengrine A, Guiliani N, Appia-Ayme C, Jedlicki E, Holmes DS, Chippaux M, Bonnefoy V: Sequence and expression of the rusticyanin structural gene from Thiobacillus ferrooxidans ATCC33020 strain. Biochim Biophys Acta 1998, I 443:99-II 2.

5. Appia-Ayme C, Guiliani N, Ratouchniak J, Bonnefoy V: Characterization of an operon encoding two c-type cytochromes, an $a a_{3}$-type cytochrome oxidase, and rusticyanin in Thiobacillus ferrooxidans ATCC 33020. Appl Environ Microbiol 1999, 65:478I-4787.

6. Yarzabal A, Brasseur G, Ratouchniak J, Lund K, Lemesle-Meunier D, DeMoss JA, Bonnefoy V: The high-molecular-weight cytochrome c Cyc2 of Acidithiobacillus ferrooxidans is an outer membrane protein. I Bacteriol 2002, I 84:3।3-317.

7. Yarzabal A, Appia-Ayme C, Ratouchniak J, Bonnefoy V: Regulation of the expression of the Acidithiobacillus ferrooxidans rus operon encoding two cytochromes c, a cytochrome oxidase and rusticyanin. Microbiology 2004, I 50:21 I3-21 23.

8. Valdés J, Pedroso I, Quatrini R, Dodson RJ, Tettelin H, Blake R 2nd, Eisen JA, Holmes DS: Acidithiobacillus ferrooxidans metabolism: from genome sequence to industrial applications. $B M C$ Genomics 2008, 9:597.

9. Elbehti A, Brasseur G, Lemesle-Meunier D: First evidence for existence of an uphill electron transfer through the $b c_{1}$ and NADH-Q oxidoreductase complexes of the acidophilic obligate chemolithotrophic ferrous ion-oxidizing bacterium Thiobacillus ferrooxidans. J Bacteriol 2000, I82:3602-3606.

10. Brasseur G, Bruscella P, Bonnefoy V, Lemesle-Meunier D: The $b_{c}$ complex of the iron-grown acidophilic chemolithotrophic bacterium Acidithiobacillus ferrooxidans functions in the reverse but not in the forward direction. Is there a second bc, complex? Biochim Biophys Acta 2002, I 555:37-43.

II. Brasseur G, Levican G, Bonnefoy V, Holmes D, Jedlicki E, LemesleMeunier D: Apparent redundancy of electron transfer path-

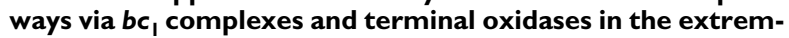
ophilic chemolithoautotrophic Acidithiobacillus ferrooxidans. Biochim Biophys Acta 2004, I 656: I I4- I 26.

12. Levican G, Bruscella P, Guacunano M, Inostroza C, Bonnefoy $\bigvee$, Holmes DS, Jedlicki E: Characterization of the pet/ and res operons of Acidithiobacillus ferrooxidans. J Bacteriol 2002, I 84:|498-I50 I.

13. Bruscella P, Appia-Ayme C, Levican G, Ratouchniak J, Jedlicki E, Holmes DS, Bonnefoy V: Differential expression of two $b c_{1}$ complexes in the strict acidophilic chemolithoautotrophic bacterium Acidithiobacillus ferrooxidans suggests a model for their respective roles in iron or sulfur oxidation. Microbiology 2007, I 53:102-I10.

14. Quatrini R, Appia-Ayme C, Denis Y, Ratouchniak J, Veloso F, Valdes J, Lefimil C, Silver S, Roberto F, Orellana O, Denizot F, Jedlicki E, Holmes DS, Bonnefoy V: Insights into the iron and sulfur energetic metabolism of Acidithiobacillus ferrooxidans by microarray transcriptome profiling. Hydrometallurgy 2006, 83:263-272.

15. Castelle C, Guiral M, Malarte G, Ledgham F, Leroy G, Brugna M, Giudici-Orticoni MT: A new Fe-oxidizing/ $\mathbf{O}_{2}$-reducing supercomplex spanning both inner and outer membranes, isolated from the extreme acidophile Acidithiobacillus ferrooxidans. Biol Chem 2008, 283:25803-258II.

16. Taha TM, Kanao T, Takeuchi F, Sugio T: Reconstitution of iron oxidase from sulfur-grown Acidithiobacillus ferrooxidans. Appl Environ Microbiol 2008, 74:6808-6810.
17. Friedrich CG, Bardischewsky F, Rother D, Quentmeier A, Fischer ]: Prokaryotic sulfur oxidation. Curr Opin Microbiol 2005, 8:253-259.

18. Frigaard NU, Dahl C: Sulfur metabolism in phototrophic sulfur bacteria. Adv Microb Physiol 2009, 54:103-200.

19. Urich T, Bandeiras TM, Leal SS, Rachel R, Albrecht T, Zimmermann P, Scholz C, Teixeira M, Gomes CM, Kletzin A: The sulphur oxygenase reductase from Acidianus ambivalens is a multimeric protein containing a low-potential mononuclear non-haem iron centre. Biochem J 2004, 38 I: | 37-146.

20. Harrison AP Jr: Genomic and physiological diversity amongst strains of Thiobacillus ferrooxidans, and genomic comparison with Thiobacillus thiooxidans. Arch Microbiol 1982, I 3 I:68-76.

21. Karavaiko GI, Turova TP, Kondrat'eva TF, Lysenko AM, Kolganova TV, Ageeva SN, Muntyan LN, Pivovarova TA: Phylogenetic heterogeneity of the species Acidithiobacillus ferrooxidans. Int J Syst Evol Microbiol 2003, 53: I I3-I I9.

22. Peng H, Yang Y, Li X, Qiu G, Liu X, Huang J, Hu Y: Structure analysis of I 6S rDNA sequences from strains of Acidithiobacillus ferrooxidans. J Biochem Mol Biol 2006, 39: I 78- I82.

23. Ni YQ, Yang Y, Bao JT, He KY, Li HY: Inter- and intraspecific genomic variability of the I6S-23S intergenic spacer regions (ISR) in representatives of Acidithiobacillus thiooxidans and Acidithiobacillus ferrooxidans. FEMS Microbiol Lett 2007, 270:58-66.

24. Bouchal P, Zdrahal Z, Helanova S, Janiczek O, Hallberg KB, MandI M Proteomic and bioinformatic analysis of iron- and sulfur-oxidizing Acidithiobacillus ferrooxidans using immobilized $\mathrm{pH}$ gradients and mass spectrometry. Proteomics 2006 I 5:4278-4285.

25. Ramirez P, Guiliani N, Valenzuela L, Beard S, Jerez CA: Differential Protein Expression during Growth of Acidithiobacillus ferrooxidans on Ferrous Iron, Sulfur Compounds, or Metal Sulfides. Appl Environ Microbiol 2004, 70:449I-4498.

26. Wakai S, Tsujita M, Kikumoto M, Manchur MA, Kanao T, Kamimura $\mathrm{K}$ : Purification and characterization of sulfide:quinone oxidoreductase from an acidophilic iron-oxidizing bacterium, Acidithiobacillus ferrooxidans. Biosci Biotechnol Biochem 2007, 71:2735-2742.

27. Kanao T, Kamimura K, Sugio T: Identification of a gene encoding a tetrathionate hydrolase in Acidithiobacillus ferrooxidans. J Biotechnol 2007, I 32: 16-22.

28. Ramirez $P$, Toledo $H$, Guiliani $N$, Jerez CA: An exported rhodanese-like protein is induced during growth of Acidithiobacillus ferrooxidans in metal sulfides and different sulfur compounds. Appl Environ Microbiol 2002, 68: I837-1845

29. Valenzuela L, Beard S, Guiliani N, Jerez CA: Differencial expression proteomics of Acidithiobacillus ferrooxidans grown in different oxidizable substrates: study of the sulfate/thiosulfate/ molybdate binding proteins. In Proceedings of the 16th International Biohydrometallurgy Symposium: 25-29 September 2005; Cape Town, South Africa Edited by: Harrison, STL, Rawlings DE, Petersen J. Compress Cape Town, South Africa; 2005:773-78.

30. Castelle C, Guiral M, Giudici-Orticoni M-T: A new acid-stable, Feoxidizing/O $/ \mathrm{O}_{2}$-reducing supercomplex spanning both inner and outer membranes, isolated from the extremophile Acidithiobacillus ferrooxidans. In Biohydrometallurgy: from the single cell to the environment Edited by: Schippers A, Sand W, Glombitza F, Willscher S. Stafa-Zurich: Trans Tech Publications Ltd; 2007:572-572.

3I. Arnesano F, Banci L, Bertini I, Martinelli M: Ortholog search of proteins involved in copper delivery to cytochrome c oxidase and functional analysis of paralogs and gene neighbors by genomic context. J Proteome Res 2005, 4:63-70.

32. Thony-Meyer L: Biogenesis of respiratory cytochromes in bacteria. Microbiol Mol Biol Rev 1997, 6 I:337-376.

33. Reniere ML, Torres VJ, Skaar EP: Intracellular metalloporphyrin metabolism in Staphylococcus aureus. Biometals 2007, 20:333-345.

34. Kiley PJ, Beinert $\mathrm{H}$ : The role of Fe-S proteins in sensing and regulation in bacteria. Curr Opin Microbiol 2003, 6: 181 - 185.

35. Elsen S, Swem LR, Swem DL, Bauer CE: RegB/RegA, a highly conserved redox-responding global two-component regulatory system. Microbiol Mol Biol Rev 2004, 68:263-279.

36. Wu J, Bauer CE: RegB/RegA, a global redox-responding twocomponent system. Adv Exp Med Biol 2008, 63 I: |3|-|48. 
37. Abdrakhmanova A, Zwicker K, Kerscher S, Zickermann V, Brandt U: Tight binding of NADPH to the 39-kDa subunit of complex is not required for catalytic activity but stabilizes the multiprotein complex. Biochim Biophys Acta 2006, I757:1676-I682.

38. Zickermann V, Zwicker K, Tocilescu MA, Kerscher S, Brandt U: Characterization of a subcomplex of mitochondrial NADH:ubiquinone oxidoreductase (complex I) lacking the flavoprotein part of the N-module. Biochim Biophys Acta 2007, I 767:393-400

39. Persson B, Kallberg Y, Oppermann U, Jornvall H: Coenzyme-based functional assignments of short-chain dehydrogenases/ reductases (SDRs). Chem Biol Interact 2003, | 43-I 44:27|-278.

40. Kervinen M, Patsi J, Finel M, Hassinen IE: A pair of membraneembedded acidic residues in the NuoK subunit of Escherichia coli NDH- I, a counterpart of the ND4L subunit of the mitochondrial complex I, are required for high ubiquinone reductase activity. Biochemistry 2004, 43:773-78I.

41. Kao MC, Nakamaru-Ogiso E, Matsuno-Yagi A, Yagi T: Characterization of the membrane domain subunit NuoK (ND4L) of the NADH-quinone oxidoreductase from Escherichia coli. Biochemistry 2005, 44:9545-9554.

42. Brandt U: Energy converting NADH:quinone oxidoreductase (complex I). Annu Rev Biochem 2006, 75:69-92.

43. Nakano T, Ikegami T, Suzuki T, Yoshida M, Akutsu H: A new solution structure of ATP synthase subunit $c$ from thermophilic Bacillus PS3, suggesting a local conformational change for $\mathbf{H}^{+}$-translocation. J Mol Biol 2006, 358: I32-|44.

44. Nicolle JLC, Simmons S, Bathe S, Norris PR: Ferrous iron oxidation and rusticyanin in halotolerant, acidophilic "Thiobacillus prosperus ". Microbiology 2009, I 55:| 302-1309.

45. Tyson GW, Chapman J, Hugenholtz P, Allen EE, Ram RJ, Richardson PM, Solovyev VV, Rubin EM, Rokhsar DS, Banfield JF: Community structure and metabolism through reconstruction of microbial genomes from the environment. Nature 2004, 428:37-43.

46. Singer SW, Chan CS, Zemla A, VerBerkmoes NC, Hwang M, Hettich RL, Banfield JF, Thelen MP: Characterization of cytochrome 579, an unusual cytochrome isolated from an iron-oxidizing microbial community. Appl Environ Microbiol 2008, 74:4454-4462.

47. Jeans C, Singer SW, Chan CS, Verberkmoes NC, Shah M, Hettich RL, Banfield JF, Thelen MP: Cytochrome $\mathbf{5 7 2}$ is a conspicuous membrane protein with iron oxidation activity purified directly from a natural acidophilic microbial community. ISME J 2008, 2:542-550.

48. Dopson M, Baker-Austin C, Bond PL: Analysis of differential protein expression during growth states of Ferroplasma strains and insights into electron transport for iron oxidation. Microbiology 2005, I 5 I:4127-4 I 37.

49. Auernik KS, Maezato $\mathrm{Y}$, Blum PH, Kelly RM: The genome sequence of the metal-mobilizing, extremely thermoacidophilic archaeon Metallosphaera sedula provides insights into bioleaching-associated metabolism. Appl Environ Microbiol 2008 , 74:682-692.

50. Auernik KS, Kelly RM: Identification of components of electron transport chains in the extremely thermoacidophilic crenarchaeon Metallosphaera sedula through iron and sulfur compound oxidation transcriptomes. Appl Environ Microbiol 2008, 74:7723-7732.

51. Bathe S, Norris PR: Ferrous iron- and sulfur-induced genes in Sulfolobus metallicus. Appl Environ Microbiol 2007, 73:249|-2497.

52. Wakai S, Kikumoto M, Kanao T, Kamimura K: Involvement of sulfide:quinone oxidoreductase in sulfur oxidation of an acidophilic iron-oxidizing bacterium, Acidithiobacillus ferrooxidans NASF-I. Biosci Biotechnol Biochem 2004, 68:2519-2528.

53. Muller FH, Bandeiras TM, Urich T, Teixeira M, Gomes CM, Kletzin A: Coupling of the pathway of sulphur oxidation to dioxygen reduction: characterization of a novel membrane-bound thiosulphate:quinone oxidoreductase. Mol Microbiol 2004, 53: I| $47-1160$.

54. Janiczek O, Zemanova J, Mandl M: Purification and some properties of thiosulfate dehydrogenase from Acidithiobacillus ferrooxidans. Prep Biochem Biotechnol 2007, 37:101-III.

55. Pronk JT, Meijer WM, Hazeu W, van Dijken JP, Bos P, Kuenen JG Growth of Thiobacillus ferrooxidans on Formic Acid. Appl Environ Microbiol I99I, 57:2057-2062.
56. Hedderich R, Hamann N, Bennati M: Heterodisulfide reductase from methanogenic archaea: a new catalytic role for an ironsulfur cluster. Biol Chem 2005, 386:96 I-970.

57. Mander G], Pierik AJ, Huber H, Hedderich R: Two distinct heterodisulfide reductase-like enzymes in the sulfate-reducing archaeon Archaeoglobus profundus. Eur J Biochem 2004 271:1106-1116.

58. Hamann N, Mander GJ, Shokes JE, Scott RA, Bennati M, Hedderich R: A cysteine-rich CCG domain contains a novel [4Fe-4S] cluster binding motif as deduced from studies with subunit $B$ of heterodisulfide reductase from Methanothermobacter marburgensis. Biochemistry 2007, 46: I 2875-I 2885.

59. Duin EC, Madadi-Kahkesh S, Hedderich R, Clay MD, Johnson MK: Heterodisulfide reductase from Methanothermobacter marburgensis contains an active-site [4Fe-4S] cluster that is directly involved in mediating heterodisulfide reduction. FEBS Lett 2002, 5 I 2:263-268.

60. Acosta M, Beard S, Ponce J, Vera M, Mobarec JC, Jerez CA: Identification of putative sulfurtransferase genes in the extremophilic Acidithiobacillus ferrooxidans ATCC23270 genome: structural and functional characterization of the proteins. OMICS 2005, 9:। 3-29.

61. Klimmek O, Kreis V, Klein C, Simon J, Wittershagen A, Kroger A The function of the periplasmic Sud protein in polysulfide respiration of Wolinella succinogenes. Eur J Biochem I998, 253:263-269.

62. Klimmek O, Stein T, Pisa R, Simon J, Kroger A: The single cysteine residue of the Sud protein is required for its function as a polysulfide-sulfur transferase in Wolinella succinogenes. Eur J Biochem 1999, 263:79-84.

63. Palenchar PM, Buck CJ, Cheng H, Larson TJ, Mueller EG: Evidence that Thil, an enzyme shared between thiamin and 4-thiouridine biosynthesis, may be a sulfurtransferase that proceeds through a persulfide intermediate. I Biol Chem 2000, 275:8283-8286

64. Mueller EG, Palenchar PM, Buck CJ: The role of the cysteine residues of Thil in the generation of 4-thiouridine in tRNA. J Biol Chem 200I, 276:33588-33595.

65. Ikeuchi Y, Shigi N, Kato J, Nishimura A, Suzuki T: Mechanistic insights into sulfur relay by multiple sulfur mediators involved in thiouridine biosynthesis at tRNA wobble positions. Mol Cell 2006, 21 :97-108.

66. Dahl C, Schulte A, Stockdreher Y, Hong C, Grimm F, Sander J, Kim R, Kim SH, Shin DH: Structural and Molecular Genetic Insight into a Widespread Sulfur Oxidation Pathway. J Mol Biol 2008 , 384: $\mid 287-1300$

67. Silver M, Lundgren DG: Sulfur-oxidizing enzyme of Ferrobacillus ferrooxidans (Thiobacillus ferrooxidans). Can J Biochem 1968 , 46:457-46I

68. Rohwerder T, Sand W: The sulfane sulfur of persulfides is the actual substrate of the sulfur-oxidizing enzymes from Acidithiobacillus and Acidiphilium spp. Microbiology 2003, 149:1699-1710.

69. Corbett $\mathrm{CM}$, Ingledew WJ: Is $\mathbf{F e}^{3+/ 2+}$ cycling an intermediate in sulphur oxidation by $\mathrm{Fe}^{2+}$-grown Thiobacillus ferrooxidans. FEMS Microbiol Lett 1987, 41:1-6.

70. Sugio $T$, Noguchi $M$, Tano $T$ : Detoxification of sulfite produced during the oxidation of elemental sulfur by Thiobacillus ferrooxidans. Agric Biol Chem 1987, 5 I:|43|-|433.

7I. Harahuc L, Suzuki I: Sulfite oxidation by iron-grown cells of Thiobacillus ferrooxidans at $\mathrm{pH} 3$ possibly involves free radicals, iron, and cytochrome oxidase. Can J Microbiol 200I, 47:424-430

72. Suzuki I, Chan CW, Takeuchi TL: Oxidation of Elemental Sulfur to Sulfite by Thiobacillus thiooxidans Cells. Appl Environ Microbiol 1992, 58:3767-3769.

73. Vestal JR, Lundgren DG: The sulfite oxidase of Thiobacillus ferrooxidans (Ferrobacillus ferrooxidans). Can J Biochem 1971, 49: I I25-I I30.

74. Suzuki I: Sulfite:cytochrome c oxidoreductase of Thiobacilli. Methods Enzymol 1994, 243:447-454.

75. Sugio T, Katagiri T, Moriyama M, Zhen YL, Inagaki K, Tano T: Existence of a new type of sulfite oxidase which utilizes ferric ions as an electron acceptor in Thiobacillus ferrooxidans. Appl Environ Microbiol 1988, 54:153-157. 
76. Sugio T, Hirose T, Ye LZ, Tano T: Purification and some properties of sulfite:ferric ion oxidoreductase from Thiobacillus ferrooxidans. J Bacteriol 1992, I 74:4189-4I92.

77. Kappler U, Dahl C: Enzymology and molecular biology of prokaryotic sulfite oxidation. FEMS Microbiol Lett 200I, 203:I-9.

78. Meyer B, Kuever J: Molecular analysis of the distribution and phylogeny of dissimilatory adenosine-5'-phosphosulfate reductase-encoding genes (aprBA) among sulfur-oxidizing prokaryotes. Microbiology 2007, I 53:3478-3498.

79. Meyer B, Kuever J: Homology modeling of dissimilatory APS reductases (AprBA) of sulfur-oxidizing and sulfate-reducing prokaryotes. PLOS ONE 2008, 3:eI5I4.

80. Hipp WM, Pott AS, Thum-Schmitz N, Faath I, Dahl C, Truper HG Towards the phylogeny of APS reductases and sirohaem sulfite reductases in sulfate-reducing and sulfur-oxidizing prokaryotes. Microbiology 1997, I43:289|-2902.

8I. Yu Z, Lansdon EB, Segel IH, Fisher AJ: Crystal structure of the bifunctional ATP sulfurylase-APS kinase from the chemolithotrophic thermophile Aquifex aeolicus. J Mol Biol 2007, 365:732-743.

82. Hanna E, MacRae IJ, Medina DC, Fisher AJ, Segel IH: ATP sulfurylase from the hyperthermophilic chemolithotroph Aquifex aeolicus. Arch Biochem Biophys 2002, 406:275-288.

83. Valdés J, Pedroso I, Quatrini R, Holmes DS: Comparative genome analysis of Acidithiobacillus ferrooxidans, $A$. thiooxidans and $A$. caldus: insights into their metabolism and ecophysiology. Hydrometallurgy 2008, 94: I80-184.

84. Bisson R, Schiavo G: Slime mold cytochrome c oxidase. An example of environmental influence on subunit composition of a eukaryotic oxidase. Ann N Y Acad Sci I988, 550:325-336.

85. Schiavo G, Bisson R: Oxygen influences the subunit structure of cytochrome $c$ oxidase in the slime mold Dictyostelium discoideum. J Biol Chem 1989, 264:7129-7I34.

86. Bisson R, Vettore S, Aratri E, Sandona D: Subunit change in cytochrome $c$ oxidase: identification of the oxygen switch in Dictyostelium. Embo J 1997, 16:739-749.

87. Friedrich CG: Physiology and genetics of sulfur-oxidizing bacteria. Adv Microb Physiol 1998, 39:235-289.

88. Aiba $\mathrm{H}$, Adhya $\mathrm{S}$, de Crombrugghe B: Evidence for two functional gal promoters in intact Escherichia coli cells. J Biol Chem I98I, 256: I1905-11910.

89. ArrayExpress transcriptomic database [http://www.ebi.ac.uk/ microarray-as/aer/]

90. Genesis genesisclient description shtml

91. Peterson JD, Umayam LA, Dickinson T, Hickey EK, White O: The Comprehensive Microbial Resource. Nucleic Acids Res 200I, 29:123-125.

92. Alm EJ, Huang KH, Price MN, Koche RP, Keller K, Dubchak IL, Arkin AP: The MicrobesOnline Web site for comparative genomics. Genome Res 2005, I5:1015-1022.

93. Jensen LJ, Kuhn M, Stark M, Chaffron S, Creevey C, Muller J, Doerks $\mathrm{T}$, Julien $\mathrm{P}$, Roth $\mathrm{A}$, Simonovic M, Bork $\mathrm{P}$, von Mering C: STRING 8 - a global view on proteins and their functional interactions in 630 organisms. Nucleic Acids Res 2009:D4 I2-4I6.

94. Ashburner M, Ball CA, Blake JA, Botstein D, Butler H, Cherry JM, Davis AP, Dolinski K, Dwight SS, Eppig JT, Harris MA, Hill DP, IsselTarver L, Kasarskis A, Lewis S, Matese JC, Richardson JE, Ringwald M, Rubin GM, Sherlock G: Gene ontology: tool for the unification of biology. The gene ontology consortium. Nature Genet 2000, 25:25-29.
Publish with Bio Med Central and every scientist can read your work free of charge

"BioMed Central will be the most significant development for disseminating the results of biomedical research in our lifetime. "

Sir Paul Nurse, Cancer Research UK

Your research papers will be:

- available free of charge to the entire biomedical community

- peer reviewed and published immediately upon acceptance

- cited in PubMed and archived on PubMed Central

- yours - you keep the copyright
BioMedcentral 